\title{
EL PROBLEMA DEL MORALISMO LEGAL EN EL DERECHO PENAL
}

\author{
The problem of legal moralism in criminal law
}

Javier Gallego Saade*

Resumen: El trabajo hace una revisión del alcance del principio del daño y su límite en el así denominado 'moralismo legal' en la discusión sobre la legitimación material de la práctica punitiva, en el contexto del derecho penal norteamericano. De ese modo, el análisis pretende abordar la discusión más general sobre la separación entre el derecho y la moral, la cual adquiere, según el autor, especial relevancia con ocasión de la reciente resolución del Tribunal Constitucional chileno que rechaza el recurso de inaplicabilidad deducido en contra del art. 365 del Código Penal chileno, que describe el delito de sodomía.

Palabras Clave: Moralismo legal - principio del daño - bien jurídico - delitos sexualessodomía consentida.

\begin{abstract}
The article provides an overview of the harm principle and its limit in the socalled "legal moralism", in the context of the anglo-american debate on the legitimacy of the punitive practice. The article aims to address the more general discussion about the separation between Law and Morals, which, according to the author, attains a special significance due to the recent chilean Constitutional Court ruling that upheld constitutionality of article 365 of the chilean Criminal Code, that regulates consensual sodomy..
\end{abstract}

Keywords: Legal moralism- harm principle- legal goods - sexual offences- consensual sodomy

"La imposición de una vida sexual idéntica para todos ... pasa por alto las discrepancias que presenta la constitución sexual innata o adquirida de los hombres, privando a muchos de ellos de todo goce sexual y convirtiéndose asi en fuente de grave injusticia. El efecto de estas medidas restrictivas podría consistir en que los individuos normales, es decir, constitucionalmente aptos para ello, volcasen todo su interés sexual, sin merma alguna, en los canales que se le han dejado abiertos. Pero aun el amor genital heterosexual, único que ha escapado a la proscripción, todavía es menoscabado por las restricciones de la legitimidady la monogamia. La cultura actual nos da claramente a entender que sólo está dispuesta a tolerar las relaciones sexuales basadas en la unión única e indisoluble entre un hombre y una mujer, sin admitir la sexualidad como fuente de placer en sí, aceptándola tan sólo como instrumento de reproducción humana que hasta ahora no ha podido ser sustituido."

Sigmund Freud ${ }^{1}$

\footnotetext{
* Egresado de Derecho, Universidad de Chile. Parte de este artículo surge del trabajo realizado en el taller de memoria "Problemas Generales de la Parte Especial del Derecho Penal" a cargo del profesor Antonio Bascuñán R. en la Facultad de Derecho de la Universidad de Chile. Correo electrónico: javierg.saade@gmail.com
} 
Gallego - El problema del legalismo legal en el derecho penal

"Entretanto, convendría que los hombres y las mujeres recordasen en las relaciones sexuales,
en el matrimonio y en el divorcio, la práctica de las virtudes ordinarias de la tolerancia, la
amabilidad,
la sinceridady la justicia. Los que, conforme a patrones convencionales, son sexualmente
bonestos, se
consideran con demasiada frecuencia no obligados a proceder como seres humanos decentes. La
mayoría
los moralistas han tenido tal obsesión con el sexo que han descuidado otras clases de proceder
éticamente recomendables y mucho más útiles socialmente."
Bertrand Russell ${ }^{2}$

\section{DERECHO CONSTITUCIONAL Y DERECHO PENAL}

En la resolución del 4 de enero de 2011, ${ }^{3}$ el Tribunal Constitucional chileno asumió la tarea de verificar que el delito de sodomía del art. 365 del código penal chileno se correspondía con las normas constitucionales. Para ello debía mostrar que la norma no vulneraba derechos fundamentales, en particular el derecho a la igualdad $\left(19 \mathrm{n}^{\circ} 2\right)$, a la vida privada $\left(19 \mathrm{n}^{\circ} 4\right)$ y a la libertad $\left(19 \mathrm{n}^{\circ} 7\right)$. El voto de mayoría concluyó que la norma no vulneraba ninguno de estos derechos y rechazó el recurso de inaplicabilidad deducido. Esto ciertamente elevará el status de la norma penal ahora que se ha declarado su conformidad con la Constitución.

Si bien el requirente menciona, a propósito de la historia de la norma penal y su consagración en textos legales anteriores que ésta "es reflejo de la represión sexual que existe en nuestra legislación, donde la justificación moral encubierta de unos pocos impide la participación consentida de personas en una relación homosexual", esta forma de argumentación, que hace referencia a una "justificación moral encubierta" no es utilizada por el Tribunal para construir su decisión. En lo que respecta al derecho a la igualdad, el voto de mayoría recurre a un interés gubernamental legítimo - en este caso expresado en el así llamado "interés superior del niño" - para mostrar el vínculo racional con la diferenciación en que incurre la norma de comportamiento. ${ }^{4}$ Respecto al derecho a la vida privada, el interés en el resguardo de la integridad del menor púber es invocado para apoyar la tesis del carácter no absoluto del derecho a la privacidad, que admite intromisiones por medio de la consagración de normas penales como la que en

\footnotetext{
${ }^{1}$ Freud, S., El malestar en la cultura, (trad. Luis López-Ballesteros), Ed.Folio S.A., 2007, p. 60

2 Russell, B., Por qué no soy cristiano y otros ensayos, edhasa, 2008, pp. 230 - 231

${ }^{3}$ Tribunal Constitucional, Rol 1683, 4 de enero de 2011.

${ }^{4}$ Considerandos $26^{\circ}-34^{\circ}$. Se afirma en el considerando $34^{\circ}$ : "no puede estimarse (...) que exista una discriminación arbitraria y, por ende, carente de razonabilidad, en la tipificación del delito de sodomía, al que se refiere la gestión judicial pendiente. Ello, porque, como se ha expresado, revela la intención actual del legislador de proteger la indemnidad de un menor de edad varón, por el impacto que la conducta típica reviste en su desarrollo psicosocial."
} 
este caso se somete a escrutinio. ${ }^{5}$ Por último, el derecho a la libertad personal, en opinión del Tribunal, no alcanza a la libertad de autodeterminación sexual - la cual el requirente estimaba como el origen de una consideración a favor de la legitimidad material de los delitos sexuales en general, y entonces consagrado en la dimensión constitucional - ni a una manifestación más abstracta como es el reconocimiento del libre desarrollo de la personalidad; en términos materiales la norma consagra un derecho de libertad ambulatoria. ${ }^{6}$

El voto de minoría al ofrecer un análisis de la norma propone una interpretación estructural, que asume el así llamado paradigma clásico liberal en el sentido de que enfatiza el sometimiento en democracias constitucionales de la aplicación del criterio de legitimidad material del ius puniendi que corresponda, a los preceptos de la norma constitucional. Introducir esta concepción permite luego de modo coherente situar el origen del discurso sobre la legitimidad material del cuerpo de delitos sexuales del código penal chileno en los principios

\footnotetext{
${ }^{5}$ Considerando $41^{\circ}$ : "en vista de una finalidad fundada y razonable, el ordenamiento jurídico chileno contempla la posibilidad de que el derecho a la privacidad esté afecto a limitaciones legales. (...) En ese contexto, la protección de la privacidad cede frente a un menor de edad que no tiene ni la madurez ni la capacidad suficiente para ponderar las consecuencias de una conducta que pugna con la actual escala de valores preponderante en la sociedad chilena" (énfasis añadido)

${ }^{6}$ Considerando 50: "es posible afirmar que el Constituyente de 1980 no entendió el derecho a la libertad personal como comprensivo del derecho al libre desarrollo de la personalidad ni menos de la autodeterminación sexual."

${ }^{7}$ Considerando $16^{\circ}$ (Voto de minoría): “cuando el legislador determina el ámbito de lo punible, estableciendo qué conductas son delitos según rangos de edad y qué edades se instituyen como límite de punibilidad, debe hacerlo al amparo de la Constitución (...) Es decir, el legislador al restringir derechos por medio del derecho penal, no puede establecer diferencias arbitrarias fundadas exclusivamente, por ejemplo, en el sexo u orientación sexual de las personas." Como se sabe, las bases constitucionales tanto de la legitimidad formal como material del derecho punitivo se pueden encontrar en el art. $19 \mathrm{n}^{\circ} 3$ de la Constitución. La cuestión de la relación entre el derecho penal y la constitución se torna particularmente interesante cuando en sistemas jurídicos, como el chileno, se cuenta con organismo que ejercen jurisdicción constitucional. Sobre esto fundamental Tiedemann, K., Constitución y Derecho penal, Revista española de derecho constitucional, Año 11, n³3, 1991, pp. 145 - 171, discutiendo la relación a propósito de la definición de pena, el contenido de principios fundamentales y la legitimación procedimental. Ahora bien, respecto de la legitimación material, la identidad entre el objeto de referencia tanto de los valores que se plasman en la norma constitucional como lo que se deriva del desempeño de los bienes jurídicos logra que éstos se relacionen de modo estrecho. Sin embargo, es necesario conceder que, fuera de la dogmática, ello no es suficiente. Por esta razón desarrolla de modo lúcido los problemas que trae el espacio de discreción que gozan los tribunales constitucionales - considerando que el bien jurídico no se encuentra por lo general consagrado explícitamente en las normas constitucionales - a propósito precisamente de las primeras incursiones del Tribunal Constitucional Alemán frente a la norma penal contra la sodomía, Bernd Schünemann. Lamenta el autor que el espacio discrecional le permita al Tribunal esperar a observar un auténtico cambio en la moral de la sociedad antes que verse amarrado o sometido al potencial crítico del bien jurídico. Schünemann, B., El principio de protección de bienes jurídicos como punto de fuga de los límites constitucionales de los tipos penales y de su interpretación, en Hefendehl, R., (ed.) 'La teoría del bien jurídico', Marcial Pons, Madrid, Barcelona, 2007, pp. 209 y ss.
} 
fundamentales de la Constitución, que declaran la igual dignidad de las personas, y la necesidad de promoción de su mayor realización espiritual (Considerando $19^{\circ}$ ). Estas preconcepciones apoyan por último la consagración del ideal liberal de neutralidad respecto a las concepciones del bien, en concordancia con una teoría moderna de la justicia política, que se consagra a nivel institucional en la norma constitucional. ${ }^{8}$ Este criterio al hacerse operativo como herramienta de crítica reclama la ilegitimidad de la afirmación, por parte del legislador, de "determinados criterios culturales sobre aquello que se considera "aceptable"” (Considerando $21^{\circ}$ ) en el ejercicio de su prerrogativa exclusiva de definición y tematización de las conductas punibles. Este argumento volverá más adelante en el voto de minoría, cuando sus redactores concluyan en contra del rol del interés superior del niño como principio pragmático, que no se demuestra la necesaria conexión intensa entre la norma y el fin gubernamental de modo de tolerar la discriminación por orientación sexual, por la razón de que, la auténtica consideración pragmática, se sincera con la institucionalización de un "prejuicio rotundo acerca de la condición homosexual (..), connotándola negativamente desde el ámbito cultural" (Considerando $\left.47^{\circ}\right)$. Si se mira con atención el argumento', se notará que se trata de la misma aproximación al problema de la discriminación por orientación sexual en sede constitucional que en 1996 la Corte Suprema norteamericana resolvió en Romer v. Evans ${ }^{10}$, dando el paso para permitir revocar la decisión previa en Bowers v. Hardwick $^{11} \mathrm{y}$ entonces declarar en el célebre Lawrence v. Texas ${ }^{12}$ que el delito de

\footnotetext{
8 Considerando 20: "la Constitución chilena no prejuzga sobre la orientación sexual de los ciudadanos ni sobre las prácticas sexuales que, libremente, éstos estimen conveniente efectuar en su vida privada."No se hace explícito en este considerando el aparato conceptual de filosofía política que apoya el argumento, mas el ejercicio de búsqueda de la meta-reflexión da como resultado el principio de neutralidad, al que haremos referencia más adelante. Desde ya véase Sadurski, W., Theory of punishment, social justice, and liberal neutrality, Law and Philosophy, Vol. 7, N³, $1988-1989$, donde se propone un compromiso con el ideal de neutralidad (que prohíbe intervenciones penales paternalistas o moralistas) como solución al problema de justificación, antes que al problema de legitimación material.

${ }^{9}$ Y se considera además el uso de la noción "categoría sospechosa" para referirse al atributo de orientación sexual, (Considerando $18^{\circ}$ ) célebremente invocado en los casos de la Corte Suprema de Estados Unidos que a continuación se mencionan, y la referencia más adelante al caso Lawrence $v$. Texas en la sección dedicada a recopilar sentencias de tribunales superiores extranjeros relevantes (Considerando $29^{\circ}$ )

10517 U.S. 620 (1996). La Corte Suprema consideró que una enmienda constitucional estatal prohibiendo adoptar legislación proteccionista dirigida a ciertos individuos sobre la base de su orientación sexual vulneraba la cláusula de igual protección ante las leyes - contenida en la XIV Enmienda de la Constitución - puesto que no aparecía suficientemente demostraba la existencia de ningún interés estatal legítimo más allá de la evidente animosidad dirigida hacia los individuos de orientación homosexual que la enmienda institucionalizaba. Notable resulta que la principal opinión disidente en dicho caso destaca la preservación de una moral tradicional culturalmente cargada hacia la heteronormatividad como principal argumento para rechazar la declaración de inconstitucionalidad de la enmienda constitucional ["The constitutional amendment before us here is not the manifestation of a 'bare...desire to harm' homosexuals, but is rather a modest attempt by seemingly tolerant Coloradans to preserve traditional sexual mores"]

11478 U.S. 186 (1986)

12539 U.S. 558 (2003)
} 
sodomía (en el fallo del caso Bowers consagrado como norma amparada por la Constitución) vulneraba el derecho - jurisprudencialmente construido - a la vida privada, y fundamentalmente, la garantía de igual protección de la XIV Enmienda de la Constitución. ${ }^{13} \mathrm{La}$ diferencia con nuestra realidad radica en que en todos estos

${ }^{13}$ El voto disidente en Bowers lo lleva adelante el Juez Blackmun; se le unen Brennan, Marshall y Stevens. El argumento es el siguiente: es necesario recalcar de modo apropiado la cuestión que sirve de base al argumento sobre la punibilidad de las relaciones sexuales sodomíticas. No puede decirse que el derecho que reclaman los involucrados en este caso sea simplemente el de verse involucrado en un acto sexual no convencional (distinto del coito marital heterosexual), sino más bien el elemento central que hace de éste un caso difícil es el contexto en el que es posible que cualquier individuo, en tanto ciudadano, desarrolle una actividad en privado que no cause ni directa ni indirectamente daño a otros. Si permitimos considerar como objeto de la discusión, en términos del hecho fáctico cuya constatación permite la subsunción del caso al enunciado de la norma penal, el desenvolvimiento en privado de los ciudadanos y las actividades 'no-dañosas' que tienen lugar en ese contexto, entonces venceremos - dice el argumento - la opacidad propia del punto de vista inverso: aquél que sólo ve actos concretos y pone la satisfacción del enunciado de la norma penal antes que la apreciación del contexto en el que ocurren dicho actos, y es ciego -entonces- a la realidad de que dicha apreciación permite la deducción de un derecho derivado: el así llamado "derecho a la privacidad", o bien "derecho a la libertad de agencia en la esfera privada". O por último y de modo más elocuente, en las propias palabras del Juez Blackmun: "el derecho a ser dejado en paz”. El desarrollo de este derecho a 'ser dejado en paz' procede a través de su deducción de los mandatos establecidos en la jurisprudencia de la Corte. Se trata, entonces (y a diferencia de lo que ocurre en nuestro derecho constitucional donde aparece explícitamente reconocido en el catálogo de derechos fundamentales) de un derecho construido jurisprudencialmente. Según Blackmun, la Corte ha desarrollado el argumento a este respecto en dos líneas diferentes (pero complementarias). Por un lado, ha establecido que es propio que el Estado y el derecho punitivo que le asiste, encuentren un límite en el ejercicio legítimo de aquellas decisiones que interesan al individuo y que resultan cruciales para su desarrollo. En relación a esto, también debe reconocerse que están lejos de este alcance ciertos lugares y contextos en los cuales es posible el desarrollo libre del individuo. Todo esto conforma un complejo de intereses que recibe el nombre de 'interés en la privacidad' (Privacy interest) que se erige como límite a la agencia de otro, que en caso de impedir u obstaculizar la satisfacción de dicho interés, se constituye en causa del daño que sufre quien adopta el interés (ciertamente instrumental) como elemento definitorio de su propia personalidad. Siguiendo esta línea, el argumento disidente prosigue con la introducción del concepto de 'reforzamiento de la moral' (enforcement of morals) por parte del derecho, como un ejemplo del significado simbólico de la norma penal aquí en cuestionamiento constitucional. Es natural que así sea pues frente al reforzamiento penal de una norma de comportamiento, sea cual sea el origen cultural de su establecimiento, el argumento debe sobrepasar el umbral de la mera postulación de un deber de no interferencia en la esfera privada de los ciudadanos; puesto que no existe ni es posible que exista un deber irrestricto de no interferencia que esté obligado a seguir, por ejemplo, el funcionario encargado de la investigación y denuncia de los hechos criminales. Con la introducción de tal interés legítimo se está afirmando la propiedad moral de un derecho subjetivo que cuestiona la legitimidad constitucional del reforzamiento penal de un comportamiento. No es, en principio, 'el comportamiento en sí mismo' el evaluado a través de la operatividad de un criterio de corrección normativa moral sino su inclusión o exclusión a los estándares de evaluación jurídicos a través del reconocimiento de la esfera privada como filtro. La idea de que existe al menos un interés legítimo a la vida privada descansa, por tanto, en una consideración ulterior. En esta consideración ulterior sí nos interesa la evaluación del comportamiento y el origen cultural de la adscripción de un significado, en este caso, a los actos sexuales (privados). Para el voto disidente, el criterio de evaluación aquí sólo puede ser moral; en el sentido de que es deseable un cierto 
Gallego - El problema del legalismo legal en el derecho penal

casos los fines legítimos que el Estado reclamaba y sostenía aseguraba con las respectivas normas sometidas a escrutinio por la Corte, resultaron controvertidos y contrastados con la pretendida protección de una forma de moral convencional, represiva de formas de expresión sexual distintas al coito vaginal heterosexual. ${ }^{14}$ Es

disenso respecto del sentido que cabe adscribir al ejercicio de una determinada práctica sexual, en términos de 'reflejo' de una cierta identidad cultural. Para el voto disidente sin embargo, ello no puede significar que la institucionalización de una determinada práctica por parte de la corrección jurídica, además de publicitar el ejercicio de dicha práctica (sexual privada), la torne precaria. Es decir, no puede decirse que el proceso de reflejo, de ver reflejadas en nuestra identidad cultural la condena o aprobación de una práctica, se torna precario ante la institucionalización normativa del ejercicio mismo de dicho reflejo. En este sentido, se apela a la independencia del juicio moral respecto del jurídico. Véase para una exposición de los argumentos la sección 'Homosexuality', de Dworkin, G., (Ed.) Morality, Harm and the Law, Westview Press, pp. 93 - 104. Ahora bien, el célebre caso Lawrence tiene lugar casi veinte años después en el estado de Texas en vez de Georgia. Los hechos tienen lugar en la ciudad de Houston, donde oficiales de policía, en respuesta a una llamada sobre un supuesto desorden por armas, ingresaron a la vivienda de John G. Lawrence. La policía encontró a Lawrence teniendo sexo con otro hombre, el Sr. Garner. La norma penal cuya contravención justificó el arresto de ambos fue aquella del Código Penal de Texas que sanciona el 'coito desviado' (deviate sexual intercourse) entre personas del mismo sexo. Se define este acto como: “(a) Cualquier contacto entre cualquier parte de los genitales de una persona y la boca o ano de otra persona; o (b) La penetración de los genitales o el ano de otra persona con un objeto". Es decir, y adelantándonos algún tramo en la discusión, podemos afirmar que la norma penal del estado de Texas que sanciona el coito desviado, adopta una postura propia del paradigma del acto sexual de la teología moral de la escolástica, es decir, aquella para el cual "el orden natural del comportamiento sexual es el coito heterosexual vaginal”, que encuentra, por tanto, dos formas de 'desviación' cuya manifestación debe prevenirse por medio de una amenaza penal: el placer sexual extramatrimonial, por un lado, y el placer sexual antinatural. En el caso específico de la norma, el coito 'desviado' satisface la descripción de un acto antinatural, pues contraviene las dos exigencias del paradigma: la introducción del miembro masculino en la cavidad vaginal femenina, y la ejecución de este acto preciso por parte de un hombre y una mujer. El voto de mayoría lo llevó adelante el Juez Kennedy. Podemos apoyarnos para describir el argumento en la misma estructura que armó el adjudicador, donde la respuesta a una de las preguntas que se plantea (¿Existe algún interés legítimo vulnerado con la prohibición de actos sexuales consentidos por adultos y ejecutados en privado?) se construye sobre la base de la reproducción del propio razonamiento de la Corte en fallos anteriores, de modo tal de hacer una deducción 'jurisprudencial' de un derecho a 'ser dejado en paz' o mejor (en las palabras de Kennedy) un 'derecho a la privacidad' cuyo contenido se expresa en una diversidad de actividades; entre ellas, manifestaciones de la llamada 'autonomía sexual'. El precedente citado comprende Griswold v. Connecticut (uso de drogas y anticonceptivos como parte de la planificación familiar) y los posteriores Eisenstaed $v$. Baird y el célebre Roe v. Wade. La conclusión del análisis de estos fallos (que por lo demás son anteriores al propio Bowers, que entonces de algún modo lo comprometen) es simplemente la consagración que haría explícita Blackmun, de un derecho a la privacidad con contenido indeterminado. Es decir, un 'derecho abstracto a la privacidad'. Para una exposición de las opiniones de los jueces en este fallo en castellano, véase Vial, Tomás, Homosexuales y autonomía sexual en la jurisprudencia reciente de la Corte Suprema norteamericana: El caso Lawrence v. Texas, en Revista Derecho y Humanidades $\mathrm{n}^{\circ} 10$, Universidad de Chile, Escuela de Derecho, 2004, pp. 235 - 249. Volveremos sobre la importancia de estos fallos a la luz de la reciente decisión del Tribunal constitucional, cuando contemos con el aparato conceptual sobre moralismo necesario para abordarlos apropiadamente.

${ }^{14}$ De todos modos Lawrence v. Texas nunca dejó de ser un caso difícil. El resultado consideraba numerosos factores, y el posible impacto de la decisión en la opinión pública (los mismos 
decir, en estos casos las opiniones de la mayoría (y los disidentes en Bowers) asumen el problema que la instauración del denominado 'moralismo legal' como criterio legitimador impone al derecho constitucional. Hace explícito lo que está implícito en el voto de minoría del fallo del Tribunal constitucional chileno.

En nuestro derecho, este problema ha sido asumido parcialmente por Nicolás Oxman, quien asume como punto de partida el principio de neutralidad liberal institucionalizado en la norma constitucional para retomar la discusión sobre la capacidad de rendimiento del criterio de legitimación material continental a propósito del reforzamiento de la moral por el derecho penal (o constitucional). ${ }^{15}$

El primer capítulo del libro contiene consideraciones generales sobre la capacidad de rendimiento del criterio de legitimidad material continental en lo que respecta a la distinción entre la lesión a esferas de autonomía y la protección o reforzamiento de valores. Luego en el segundo capítulo se defiende la tesis de la inadmisibilidad de la protección de valores morales en el marco de un Estado (constitucional) de derecho, y luego se desarrolla la discusión y las diversas interpretaciones del contenido y rendimiento del bien jurídico protegido en el cuerpo de delitos sexuales, cuestión que no comentamos aquí. Termina con un tratamiento de la norma penal referida al almacenamiento de pornografía infantil. ${ }^{16}$

Desde un principio se descarta la posibilidad de que, bajo la lógica de la protección de intereses colectivos utilizando el criterio de legitimidad continental, el orden moral de una sociedad, (que puede ser) entendido como un conjunto de valores operativo como criterio de corrección, resista ser elevado de modo coherente a dicha categoría. La interpretación del rol que juega, en términos analíticos, la idea de lesividad (como una categoría sólo comprensible una vez que se supone como esquema de trabajo la relación vertical entre persona y Estado) es claramente liberal - se apoya en Hassemer. ${ }^{17}$ En todo caso, la cuestión no se llega a desarrollar de modo suficiente como para desprender el favorecimiento de dicha reconstrucción analítica del problema. La cuestión central aparece más adelante,

problemas que enfrentaron los jueces en Brown v. Board of education). El resultado, por tanto, estuvo lejos de ser una automática aplicación de los principios asentados tras Romer v. Evans. Del mismo modo, no puede preverse que Lawrence incidirá de modo decisivo en una decisión favorable a la constitucionalidad del matrimonio homosexual por parte de la Corte Suprema. Sobre esto Klarman, M., Brown and Lawrence (and Goodridge), Michigan Law Review, Vol. 104, n³3, 2005, en particular pp. 436 - 440.

15 Oxman, N., Libertad sexual y estado de derecho en Chile, $1^{\text {a }}$.Ed. Librotecnia, Santiago, Chile, 2007.

16 Sobre esto último existe de la misma editorial un trabajo monográfico reciente. Sanchez, C., Delito de almacenamiento de pornografía infantil, Librotecnia, Santiago, Chile, 2010.

17 Oxman, Op.Cit., p. 35. En todo caso, la cuestión es problemática pero por el hecho de que el potencial explicativo o crítico del binomio bien jurídico individual/colectivo se queda corto ante ciertas conductas tematizadas jurídico-penalmente que admiten una u otra descripción o bien manifiestan un solapamiento. Así lo explica Hörnle, T., La protección de sentimientos en el STGB, en Hefendehl, R., (ed.) 'La teoría del bien jurídico', Marcial Pons, Madrid, Barcelona, 2007, pp. 383 399. 
cuando llega el momento de hacerse cargo de la teoría del bien jurídico como aparato conceptual crítico o criterio de corrección de la prerrogativa del legislador de tematización de conductas penalmente relevantes. Apoyado en doctrina española, favorece el autor la idea de que le legislador en la práctica no se somete al criterio de legitimación como estándar normativo sino que burla la exigencia de explicitar los estados de cosas valiosos introduciendo elementos normativos en la descripción de los tipos o atendiendo al estado de cosas en la dimensión social ${ }^{18}$ (¿Qué puede hacer el legislador al pretender, desde el punto de vista pragmático, introducir una valoración al momento de ejercer su prerrogativa de tematización, sino atender al estado de la cuestión en la sociedad? Ahora bien, claramente la cuestión hace alusión más bien a la escasa capacidad de rendimiento del criterio de legitimación en oposición al rol persuasivo que cumple el discurso políticocriminal en sociedades modernas). En lo que respecta al derecho constitucional, la cuestión de nuevo se resuelve en la dimensión teórica, en la que puede o no estar situado el legislador. Según Oxman, aquí éste se encuentra amarrado a la necesidad de explicitar el vínculo entre el estado de cosas protegido, y el valor correlativo (o principio programático) que se consagra en la norma constitucional. Afirma también la importancia de evitar la identificación absoluta entre uno y otro catálogo, puesto que la imposición de deberes de respeto a los derechos que se superponen en ambos catálogos secunda al reconocimiento de los mismos por parte de la norma constitucional. ${ }^{19}$

Luego de desarrollar las tesis funcionalistas ${ }^{20}$ que arrojan dudas sobre el privilegio de la teoría del bien jurídico como criterio de legitimidad material en la esfera continental, Oxman refuerza el rol que cumple esta teoría precisamente en la determinación precisa de los contornos entre el derecho y la moral, y ello le permite (incorporando el trabajo previo relativo a la relación entre derecho constitucional y prerrogativa legislativa de determinación de estados de cosas

\footnotetext{
${ }^{18}$ Ibid., p. 46. En esto llega a la misma conclusión que Schünemann en Op. Cit. (supra nota 7) pero refiriéndose al rol de intérprete de la ley del Tribunal Constitucional cuando aquí hablamos de función legislativa.

${ }^{19}$ Ibid., pp. 47 - 49. Si asumimos como paradigma la manifestación de la expresión de valoración en una norma de comportamiento, aquí Oxman se está acercando a dos discusiones diferentes. La primera, historiográfica, relativa a la identidad - en la dimensión teórica - entre los bienes jurídicos y los derechos fundamentales. Y la segunda, el problemático discurso contemporáneo que pretende formular normas de comportamiento a partir de la consagración de derechos fundamentales (el así llamado "paradigma alternativo" o inversión del paradigma clásico). Sobre la descripción del fenómeno y sus problemas Bascuñán, A., Derechos fundamentales y Derecho penal, en Revista de Estudios de la Justicia $\mathrm{n}^{\circ}$ 9, 2008 y Mañalich, J.P., La probibición de infraprotección como principio de fundamentación de normas punitivas. ¿Protección de los derechos fundamentales mediante el derecho penal?, en Revista Derecho y Humanidades, No 11, Santiago, 2005. Finalmente la tesis de Oxman será que la sólo la libertad sexual como bien jurídico es concordante con dos ordenamientos que se amparan en la norma constitucional. Se trata del derecho humano a la sexualidad, y el derecho fundamental a la libertad del art. $19 \mathrm{n}^{\circ} 7$ del catálogo de derechos de la Constitución. Notable es el resultado al contrastar esta interpretación del origen del valor protegido en la norma constitucional con la interpretación del Tribunal constitucional, que como pudimos observar, descarta esta tesis.

${ }^{20}$ Oxman, Op.Cit., pp. $54-64$.
} 
valiosos protegidos, aunque no lo hace explícito en este párrafo) favorecer la tesis de la inconstitucionalidad del delito del art. 365 del código penal, ${ }^{21}$ desde la perspectiva pragmática, no asumida (como vimos) ni por la mayoría ni por los disidentes (o sólo parcialmente por estos últimos) en el fallo del Tribunal constitucional. Esta consideración volverá, a su vez, en el capítulo segundo, el cual, luego de describir el rol de la política criminal expansiva en la definición del nuevo cuerpo de delitos sexuales en la práctica punitiva chilena, ${ }^{22}$ reconoce en el delito de sodomía un delito contra la moral ("sin víctima") cuya estructura de autoría sólo reconoce coautores. ${ }^{23}$ Estima que la hipótesis de la corrupción de menores sirve al propósito de encubrir ${ }^{24}$ una intención discriminatoria por parte del legislador, por cuanto la figura es "pensada exclusivamente para limitar la capacidad de autodeterminación sexual de los varones adolescentes". 25

Sin duda este trabajo monográfico debe celebrarse por cuanto desarrolla un aparato conceptual sofisticado que luego se utiliza para proveer una lectura crítica de la "parte especial de los delitos contra la moral". No obstante, fuera de la referencia a Hassemer en lo relativo a la relación entre persona y Estado como panorama favorable a la exclusión de la categorización de la moral como bien jurídico colectivo, y el constante apoyo en el principio de neutralidad liberal institucionalizado en la norma constitucional, no se enfrenta el problema del moralismo legal desde el punto de vista de la asunción del desafío de definir el alcance de dicha estrategia de justificación. ${ }^{26} \mathrm{~A}$ continuación desarrollaré la propuesta de Joel Feinberg que pretende definir al menos cuatro formas de moralismo legal. Sostengo que esta estrategia debería ser comprendida e integrada a nuestro debate académico sobre los problemas de legitimación de los delitos sexuales. En este trabajo en todo caso la aprovecharé en cambio para volver a

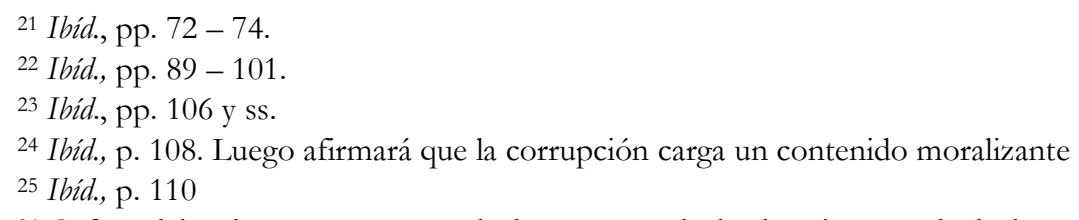

26 Sufre, al igual que gran parte de los actores de la doctrina penal, de lo que Douglas Husak denominó moral arguphobia, o sea, una fobia a introducirse en la discusión sobre el contenido y alcance de la moral cuya protección por el derecho penal ellos mismos condenan. Ponemos todos nuestros esfuerzos - dice Husak - en "conceptualizar", esto es, en hacer operativos los conceptos de 'daño' (o la idea de 'lesión de un bien jurídico') y nos olvidamos de desarrollar el aparato conceptual que sostiene aquella noción que estamos, sobre la base de estos conceptos, criticando. Husak, D., Philosophy of Criminal Law, Rowman \& Littlefield, Estados Unidos, 1987, p. 231. Esto se aprecia de modo recurrente en la doctrina chilena. Parece postularse de modo recurrente que el resultado de la meta-reflexión que corresponde sugiere que la "practicidad de la moral" como bien jurídico es insuficiente como criterio de legitimidad material. De este modo, el descubrimiento de la moral como única entidad que es objeto de protección por una norma de comportamiento opera como alerta de ilegitimidad. En ese sentido, se suele afirmar la ilegitimidad material de una norma allí donde reconozca la moral como entidad merecedora de protección. Véase la explicación de las razones por las cuales es motivo de celebración, la eliminación en el 'Anteproyecto de Nuevo Código Penal' de los delitos clásicos de mera inmoralidad, en Rodríguez C., Luis, Sobre la regulación de los delitos contra la integridad sexual en el Anteproyecto de Código Penal, Polit.Crim. n¹, A 1, p.18 
revisar discusiones (ya) clásicas sobre la radicalización de la separación entre derecho y moral. De todas formas, antes de entrar en ello es necesario revisar cuestiones fundamentales del criterio de legitimidad material desarrollado por Feinberg a partir de la obra de J.S.Mill que opera (aunque existen quienes proponen su virtual desaparición en la actualidad $)^{27}$ en la práctica punitiva angloparlante. Además de una descripción del contenido de la teoría, desarrollaré brevemente una reciente propuesta de encuentro entre ésta y el criterio continental.

\section{BIEN JURÍDICO Y PRINCIPIO DEL DAÑO}

En la obra de Joel Feinberg ${ }^{28}$ el principio del daño opera como 'filtro de legitimación' del comportamiento tematizable jurídico-penalmente. ${ }^{29} E s$ usual traducir el concepto de wrongdoing como 'injusto'. La comunidad hispano-parlante hace referencia a 'injustos' cuando apunta a la conducta que quebranta una norma de comportamiento reforzada penalmente. El injusto penal tiene dicha calidad puesto que se trata de una conducta que lesiona un bien jurídico, aquel que protege la norma de comportamiento penalmente reforzada. Entonces, donde, quienes operamos en la tradición continental, hacemos referencia a la lesión, o a la "lesividad" de una conducta, quien opera en la tradición anglosajona habla de daño o "dañosidad" del comportamiento penalmente relevante.

Feinberg concede que, en principio, catalogar de dañosa a una conducta es una tarea compleja. ${ }^{30}$ Esto, podemos decir, principalmente por el hecho de que el concepto de 'daño' porta lo que con Hart podemos llamar una amplia zona penumbral, esto es, aquella propiedad que explica que en el uso del concepto es esperable que exista desacuerdo entre hablantes competentes respecto del uso del concepto para efectos de construir oraciones con sentido y referencia. ${ }^{31}$

Por ello Feinberg intenta una suerte de taxonomía de los usos posibles del concepto de daño que agrupa tres distintos usos que recibe el concepto. En el primer uso encontramos todos los sinónimos de daño cuando son incorporados a una oración cuya referencia es cualquier objeto del mundo, y entonces se predica

\footnotetext{
27 Así Harcourt, B.E., The collapse of the harm principle, 'The Journal of Criminal Law and Criminology', Vol. 90, n¹, 1999.

${ }^{28}$ Feinberg, J., The Moral limits of the Criminal Law, Oxford University Press, Oxford, 1984. En lo sucesivo se harán referencias específicas a los respectivos volúmenes de la obra. Para una reseña de la obra que abarca los dos primero volúmenes (Harm to Others y Offense to Others) véase Amdur, R., Review: Harm, Offense, and the limits of liberty, Harvard Law Review, Vol. 98, nº, 1985, pp. 1946 1959.

29 Seher, G., La legitimación de la normas penales basadas en principios y el concepto de bien jurídico, en Hefendehl, Roland (ed.), 'La teoría del bien jurídico', Ediciones Marcial Pons, Madrid, 2007, p. 78.

${ }^{30}$ Feinberg, J., Harm to Others, p. 32.

${ }^{31}$ Hart, H.L.A., El Concepto de Derecho, Trad. Genaro Carrió, Abeledo-Perrot, Buenos Aires, pp. 155 -169 .
} 
de éste que 'está dañado' en el mismo sentido en que decimos 'esta ventana está rota (por ejemplo, por una piedra)'. De este modo decir ' $x$ está cortado, decaído, podrido, doblado, mutilado, quebrado, roto, aplastado, quebrajado, quemado, etc.' equivale a decir ' $x$ está dañado' o ' $x$ ha sufrido un daño'. Como se aprecia, resulta todavía un uso demasiado amplio en términos del espectro de referencia de las oraciones con sentido como para poder ser utilizado como criterio para satisfacer proposiciones normativas.

Por esta razón introduce Feinberg un segundo uso del concepto; el cual, en combinación con el tercero, servirán para desentrañar la verdadera utilidad del daño como criterio de legitimación material de la práctica punitiva. Se trata primero del daño como lesión de un interés (setback of an interest). Se introduce entonces un elemento nuevo: el interés. Es necesario demarcar el alcance de este concepto, y de partida la familiaridad con que se maneja en ámbitos de relaciones comerciales. Notar esto resulta, como el propio Feinberg lo afirma, de suma utilidad para comprender la relación íntima entre un interés y un individuo (es decir, la lógica de la asociación entre intereses y personas particulares que tienen esos intereses). Así, se dice respecto de una persona que tiene un interés cuando está dispuesta a asumir un riesgo (stake) en orden a proteger aquello que considera valioso. Naturalmente, en el ámbito comercial, los objetos considerados valiosos por los individuos respecto de los cuales están dispuestos a asumir un riesgo en orden a permitir su protección y pervivencia, suelen ser entidades materiales e individualizables, lo que no ocurre generalmente cuando la usanza del concepto se traslada a la ejecución de hechos brutos por parte de los individuos. Así, componentes como la 'vida' y la 'libertad personal' son considerados valiosos por quien está dispuesto correr riesgos para hacer que perduren y tiene por tanto 'interés' en ellos. Sin embargo, creo que es necesario no adelantar conclusiones, pues Feinberg afirma que las entidades respecto de las cuales se predica la asociación entidad - individuo mediada por el interés pueden ser de diversa naturaleza. ${ }^{32}$ Lo que realmente importa es la apreciación global de aquella pluralidad de estados de cosas - que constituyen o permiten el 'bienestar' de la persona respecto de los cuales uno tiene interés (en su preservación). De este modo, respecto de dicha globalidad, se apreciará una interferencia jurídico-penalmente relevante en la medida en que la acción invada o lesione dicho interés relevante desde el punto de vista del bienestar de la persona y constituya la agencia de otro (principio del daño propiamente tal) o de uno mismo (paternalismo).

El concepto de daño que hace alusión a la dimensión de lo jurídico en sentido estricto es el tercer concepto, que exige la vulneración de derechos, de los que debe ser titular el afectado, de modo de verificarse una conducta penalmente relevante. Aquí es propio hablar de 'injusto' en el sentido de que comete una injusticia quien invade el derecho (en tanto atribución de autonomía) de otro.

\footnotetext{
${ }^{32}$ Feinberg, J., Op. Cit., p. 34.
} 
En algún sentido, la entidad del daño como evento individualizable y jurídico-penalmente relevante sólo se aprecia una vez que se unifica el criterio bajo estos dos últimos usos. Es decir, sólo podemos entender el daño como un evento relevante en la medida en que el acto que lo produzca constituya a su vez un evento jurídico, en el sentido de mediar la relación entre dos agentes antes desconocidos (o no, por ejemplo en el caso de incumplimiento contractual) a través de una disposición normativa (comisión de un injusto). Sin embargo, ello no obsta a que ambos elementos: el acto dañoso en sí mismo y el acto como injusto, resistan un análisis extenso de sus componentes por separado. Así ocurre por ejemplo, para el caso de la acción dañosa, cuando consideramos todos los elementos que la componen. Para Feinberg, una acción dañosa consiste en: una acción, con un cierto contenido intencional, no excusable, que lesiona un interés, y que supone la vulneración del derecho de la víctima. ${ }^{33}$ Que el injusto parezca estar integrado en el concepto de daño como aquí lo presenta Feinberg puede inducir a confusiones. Afortunadamente más adelante el punto se ve aclarado: No todo daño es necesariamente un injusto a menos que se vea un derecho 'legal' (por exclusión a un derecho 'moral' que en estricto rigor debemos entender como una pretensión de reconocimiento de orden moral que todo individuo puede plantear a otro) vulnerado por medio de la misma acción. ${ }^{34}$

Hasta aquí la cuestión parece no exigir mayores comentarios. Sin embargo, la teoría exige en la visión de Feinberg, para asegurar su plausibilidad, lograr la intercambiabilidad entre los conceptos de daño e injusto. Sin embargo, no se pretende que esto sea posible meramente a través de la intercambiabilidad a su vez entre los conceptos interés y derecho (lo que haría de la teoría una mera reconceptualización de la idea de lesión de un bien jurídico), sino más bien, mediante la asociación del daño con una entidad abstracta pero cuya asociatividad con un titular determinado sea posible en una comunidad política (donde se entiende que hay una distribución ¿igualitaria? de esferas de autonomía). Así, la idea de pretensión de reconocimiento moral se reinterpreta como una razón valida que el ciudadano puede invocar para apoyar el ejercicio de una acción que él considera idónea para alcanzar el objetivo valioso para él.

En este punto, la similitud entre las así llamadas pretensiones de reconocimiento moral y los derechos naturales (deducidos en virtud del ejercicio de la racionalidad de la pura condición humana) resulta evidente. Y aún más, carga a la teoría con el peso de presentar un sistema moral completo y coherente, basado en un esquema de derechos naturales de este tipo. Para evitar esa (pesada) carga, la tesis elabora el concepto de intereses básicos fundamentales para la vida ${ }^{35}$, introducido un poco antes en la obra. ${ }^{36}$

\footnotetext{
${ }^{33}$ Ibid., p. 109.

34 Ibid., pp. $110-111$.

35 Ésta es la traducción que aparece en el artículo de Seher, G., Op. Cit., p. 79, del concepto de welfare interests. En lo sucesivo sin embargo, usaré el concepto de 'intereses básicos' simplemente.

${ }^{36}$ Feinberg, J., Op. Cit., pp. 42 y ss.
} 
Estos llamados 'intereses básicos' consisten básicamente en los requisitos básicos para la mantención de una vida humana ${ }^{37}$ y suponen por tanto al menos la posibilidad de generalización. Es decir, deben tratarse de requisitos cuya característica de ser básicos y necesarios sea compartida por al menos un grupo de personas, al modo de la operatividad de un principio de universalización. Ahora bien, esto no obsta al hecho de que puedan tratarse, por cierto, de medios necesarios para alcanzar otros objetivos ulteriores, y de que permitan conformar una razón con potencial explicativo en conjunto con la idea del 'querer' (en materia de teoría de la acción).

Ahora bien, la noción de intereses básicos entendidos de cualquier modo como intereses instrumentales resulta en cualquier caso equiparable a la idea de pretensión de reconocimiento moral, y de ese modo la teoría salva la eventual objeción de la falacia naturalista. El discurso se ha tratado todo este tiempo de la existencia de ciertos intereses instrumentales y de la relación entre el quantum del daño sufrido por determinadas personas en relación a la relevancia que cierto interés básico-instrumental tiene para sí respecto de planes de vida ulteriores. Así, en palabras de Feinberg, tanto el pobre como el rico sufren un daño al ver vulnerada su propiedad, sólo que el rico sufre un daño menor que el pobre, en este sentido. $^{38}$

Aún resta elucidar de modo más acabado la idea de pretensión de reconocimiento moral, sin embargo espero avanzar en este campo más adelante, al discutir el fenómeno de la moral, y la necesaria delimitación entre el reforzamiento jurídico-penal de la prohibición de conductas dañosas en el sentido aquí expuesto, por un lado, y el reforzamiento de valores morales, por el otro.

Ahora bien, ya notará el lector que el criterio legitimatorio feinbergeriano introduce una cantidad considerable de categorías de las que prescinde la teoría del bien jurídico, que por lo general pretende relacionar el objeto valioso al que señala con el acto contrario a derecho que lo lesiona. Para algunos, parte del déficit explicativo o crítico de la teoría del bien jurídico se puede resolver si recoge ciertas nociones del principio del daño. En esa línea, y como ya lo adelantara, existe en la obra Criminalising harmful conduct ${ }^{39}$ de autoría de la profesora eslovena Nina Persak un intento precisamente - siguiendo la senda de Andrew von Hirsch ${ }^{40}$ - de encontrar un puente entre ambos criterios de legitimación.

\footnotetext{
37 Ibid., p. 37.

${ }^{38}$ Ibid., p. 112

39 Persak, N., Criminalising harmful conduct. The harm principle, its limits and continental counterparts, Springer Ed., 2007.

${ }^{40}$ La propuesta de von Hirsch se describe en Seher, G., Op. Cit., p. 81
} 
Luego de delinear de modo exhaustivo los contornos y problemáticas vinculadas al principio del daño feinbergeriano ${ }^{41}$ y a la teoría del bien jurídico, ${ }^{42}$ encontramos, ya en la conclusión, la propuesta concreta de vinculación entre ambas teorías. ${ }^{43}$ Se trata de una propuesta de recepción por parte del sistema continental del principio del daño, que -se afirma- favorecerá la operatividad de un mejor criterio normativo de revisión y corrección de las propuestas legislativas de tematización penal. Serviría también como principio limitador y de reforzamiento del principio de ultima ratio, lo que permitiría la exclusión de normas penales que regularen la autolesión o la protección de la moral. Debería también servir para limitar el catálogo de bienes jurídicos introduciendo un criterio de lesividad (¿dañosidad?) adicional. El criterio de bien jurídico no podría quedar reducido a una función puramente descriptiva. ${ }^{44}$ Luego, esta recepción sería posible en la dimensión teórica dado el punto de convergencia en la idea de 'interés' en primer lugar. En segundo lugar, resulta apoyada por el giro en ambas tradiciones hacia la protección de la autonomía individual como paradigma de justificación de la práctica punitiva estatal. ${ }^{45}$ Por último, la recepción de principios programáticos y derechos propios del derecho internacional de derechos humanos en la dimensión doméstica juega también un rol clave en el encuentro de ambos sistemas. ${ }^{46} \mathrm{En}$ la dimensión práctica la recepción requiere una asimilación del principio del daño con el de humanidad en las penas, de modo de insertarse en la práctica punitiva continental, en la determinación legal y judicial de penas y definición de conductas, y en este sentido su elevación al status de norma o principio constitucional. ${ }^{47}$

Ahora bien, al igual que Oxman, el trabajo de Persak omite un tratamiento acabado del problema del moralismo legal, ${ }^{48}$ lo que resulta lamentable considerando el provecho que podría obtenerse de la aplicación de la propuesta como aparato crítico y de resolución de este problema. Parece ser que la monografía nos deja a nosotros dicho trabajo. La cuestión es central, por ello le dedico un análisis a partir de la obra de Feinberg a continuación.

\section{EL PROBLEMA DEL MORALISMO LEGAL ...}

Según Gerhard Seher, el moralismo se caracteriza por incorporar al Derecho penal delitos sin víctima. Por lo tanto el 'objeto de protección' de la norma penal lo constituye algo así como un 'orden moral'. Asimismo afirma que el liberalismo (que como doctrina filosófico-política parece oponerse a la técnica del moralismo) resulta ser en realidad una forma de moralismo, sólo que pretende ser cuidadoso

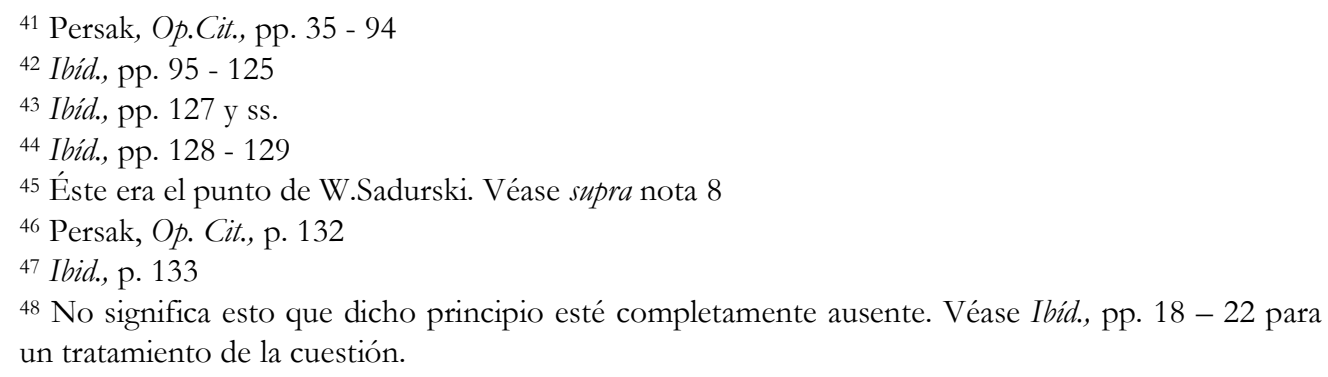


respecto de la selección de aquellos valores que merecen (han de ser) protegidos por el ordenamiento jurídico-penal. ${ }^{49}$

Para describir el así llamado moralismo legal debemos acudir al último volumen de la obra de Feinberg, Harmless Wrongdoing. ${ }^{50}$ Desde ya el título adelanta la discusión de que se hace cargo el libro. La idea de un 'injusto' que sin embargo no causa daño evoca cierta suspicacia. ¿Cómo hemos de entender la existencia de un injusto, es decir, una acción que vulnera el derecho de otro, disociado de la idea de daño? La conclusión del apartado anterior fue que estas nociones permanecían muy cerca la una de la otra de modo de proveer de consistencia al principio del daño como criterio de legitimación material en la práctica punitiva angloparlante. Puede ser que la separación venga dada por la existencia de un criterio independiente que evalúe, a la manera de una operación de corrección normativa, la justicia o injusticia de la acción. Una vez que aceptamos embarcarnos en dicha abstracción, ya no hay firmeza alguna que adelante la posibilidad de reconocimiento de alguna relación mediada por dicho criterio de corrección. Y así entonces se abre la posibilidad de que con una acción un individuo tenga la capacidad de vulnerar un orden moral y sólo eso. Ahora bien, en todo caso un poco más de finura se requerirá en este punto, relativa a la operatividad de criterios morales y la existencia de concretas normas morales - es decir, la lógica de la corrección normativa moral misma - cuestión que asumiremos más adelante. Por esta razón, la idea de que no hay daño jurídico-penalmente relevante en acciones que contravienen 'la moral' no puede por ahora (y difícilmente podrá después) llevarnos a concluir que ello significa que el agente está exento de algún juicio de reproche (moral) que se siga como consecuencia de su acción.

Por lo pronto, el título del libro adelanta el tratamiento de injustos que no dañan a otros, pero constituyen al agente en merecedor de reproche moral, siendo su procedencia independiente del hecho de que el agente actúe sobre sí mismo o materialmente lo haga sobre otros (sin causarles daño). Aunque como es evidente, el primer fenómeno constituye en realidad un caso de paternalismo (en la medida en que la intervención penal reclame alguna forma de justificación basada en la necesidad de evitación de algún daño) y el segundo requiere en la mayoría de los casos el consentimiento del otro, caso en el cual se transforma el caso en la autoría

\footnotetext{
${ }^{49}$ Seher, Op. Cit., p. 87. Me parece que esta descripción adolece de un par de defectos y debe ser tenida con cuidado, sobretodo en lo que respecta a la afirmación de que el liberalismo resulta una forma de moralismo, pues dicha afirmación contrasta con la opinión de que existen diversas formas de moralismo y diversas maneras de ser liberal, como tendremos la oportunidad de revisar más adelante en las opiniones de Michael Sandel y Moore.

50 Puede resultar útil desde ya para el lector de modo de comprender el alcance de la propuesta sobre moralismo o cualquier otro aspecto de la filosofía de Feinberg, consultar la introducción y selección de citas relevantes que se hace en el reciente trabajo de Corlett, J.A., The philosophy of Joel Feinberg, The Journal of Ethics, Vol. 10, $\mathrm{n}^{\circ} 1 / 2$, 2006. Para las citas a la obra que a continuación se discute pp. 177 - 182
} 
Gallego - El problema del legalismo legal en el derecho penal

conjunta de un atentado contra la moral. Esta última situación será la que nos interese en este trabajo. ${ }^{51}$

Es posible que una confusión inicial esté dada por el hecho de que el predicado que acompaña a la acción cuando Feinberg se refiere al moralismo ya no es injusto, sino 'mal' (evi). De este modo, se predicará de la acción que 'causa un mal' o 'es un mal' y no que causa o constituye 'un injusto'. Según Feinberg, argüir que al derecho penal le está permitido reforzar alguna norma de comportamiento cuyo contenido sea la prohibición de causar un mal y que no suponga (por tanto) dañar u ofender a otros, es contrario al programa básico del liberalismo. En todo caso, si se argumenta de este modo, se está usando el concepto (moralismo) en un

${ }^{51}$ Es casi un lugar común (y el libro de Oxman es una prueba de ello) encontrar el paradigma de los delitos contra la moral (sin víctima pero que involucran dos co-autores) en los delitos sexuales, como es el caso de la sodomía y el incesto, que requieren para configurarse - y entonces permitir demarcar la conducta que satisface estos tipos del comportamiento que exige verificarse para sancionar la conducta como violación (por ejemplo) - consentimiento por parte de los partícipes. Sin entrar todavía en la discusión sobre la calificación moral de la conducta que debería asumir el liberalismo anti-moralista, parece ser que la meta-reflexión aquí en juego dice relación con la permisibilidad moral que lógicamente se sigue respecto de una conducta sexual cuando es consentida. En esta línea Igor Primoratz ha defendido la tesis de que el liberalismo acierta al afirmar que en el consentimiento radica la base para alegar la legitimidad moral del acto sexual (en contra de tres posibles críticas a esta visión: la católica, la visión romántica de la sexualidad, y la del feminismo radical) en Primoratz, I., Sexual morality: Is consent enough?, Ethical Theory and Moral Practice, Vol.4, n³, Cultivating Emotions, 2001. Como reacción a la propuesta de Primoratz, se ha planteado que, en realidad, la tematización moral de la actividad sexual humana resulta ser una tarea mucho más compleja (de lo que Primoratz nos quiere convencer), y que no es necesario asumir una postura conservadora respecto del fenómeno de la sexualidad humana para concluir que el consentimiento de los partícipes no resulta suficiente para dotar al acto de legitimidad moral. Ello porque la sexualidad humana muchas veces presenta cierta oscuridad que demanda o exige de nosotros - para el manejo apropiado de los impulsos sexuales a modo de permitir un espacio de inter-subjetividad moralmente válido - una cierta sensibilidad ética que da lugar a ciertas obligaciones de omisión (de interacciones sexuales) que muchas veces nada tienen que ver con el consentimiento de los partícipes. Así Morgan, S., Dark Desires, Ethical Theory and Moral Practice, Vol. 6, $\mathrm{n}^{\circ} 4,2003$, pp. 377 - 410. Desde la teoría de las normas en la tradición continental, se ha presentado al consentimiento proveyendo - en contra de lo que postulan dos perspectivas tradicionales, que fijan su rol como un elemento negativo del tipo o como una causa de justificación - una base para excluir un injusto de tipo sui generis, en el sentido de aparecer como "una razón que bajo determinados presupuestos suprime la validez de la norma de prohibición respectiva" (Kindhäuser, U., Reflexiones de teoría de las normas acerca del consentimiento en el Derecho Penal, en del mismo, 'Teoría de las normas y sistemática del delito', Ara, Lima, 2008, pp. 17 - 18), lo que ciertamente reduce el valor de la discusión dogmática sobre los delitos contra la moral cuando se parte de la base de que el bien protegido sólo se deja ver - o se deja ver mejor - allí donde los participantes consienten al acto. Por último sobre este tema, la nítida separación entre casos subsumibles al espectro del principio del paternalismo por un lado, y al del moralismo por el otro, se ve enfrentada no sólo por casos en que la conducta se ejecuta en privado y en solitario (así la punibilidad del almacenamiento de pornografía infantil) sino que también por casos propios de conductas de autolesión, desde cierta perspectiva. Así se plantea la cuestión para el caso del suicidio (entre otros)en Meier, R.F., Geis, G., Criminal justice and moral issues, Roxbury Publishing Company; 4th edition, 2005, pp. 13 y ss. 
sentido bastante amplio. Feinberg propone reconocer, además de éste, un uso (más) restringido del concepto de moralismo. Según este último, el predicado que acompaña a las acciones relevantes no debe ser el de 'mal' que en sí mismo es bastante amplio sino el de 'inmoral'. Con esto se supone que al hacer referencia a la acción - ya sea se ejecute ésta en público (donde tiene la capacidad de enfrentarse de modo directo con el juicio moral sobre la rectitud de dicha acción de todos los individuos que puedan presenciar el acto) o en privado y por individuos que hubieren consentido en ello - la contrastamos necesariamente con el sistema u orden moral cuyo código deóntico se asume compartido y operativo dentro de un grupo de personas. El primero de estos tipos de moralismo se habrá de denominar moralismo en sentido amplio, y el segundo moralismo en sentido estricto. ${ }^{52}$ Este último nos interesará en lo sucesivo.

Ofrece a continuación Feinberg, basándose en esta distinción inicial entre dos formas de moralismo - que como ya observamos, descansa en la atención que un moralista pone en la naturaleza del acto que pretende reprobar, si se trata de una reprobación en sentido estricto o en sentido amplio, es decir, señalando el orden moral, o la norma moral que según su visión se ha visto vulnerada con el acto al cual dirige su reproche, o simplemente considerando la acción un mal, en sentido amplio - un nuevo criterio de distinción: la 'pureza' o 'impureza' del moralismo. Así, tanto el moralismo en sentido amplio como en sentido estricto admiten ahora una clasificación en puro e impuro.

El primero, como su nombre lo indica, sanciona conductas calificadas de 'inmorales' sin atender a otro criterio subsidiario. El orden o la norma moral se han visto contravenidos y ello es justificación suficiente (en términos de razonabilidad) para tematizar penalmente la conducta relevante. El segundo (impuro) pretende, en cambio, que a través del reproche se logre una reconducción a normas sociales, a través del principio del daño. Es decir, entiende que la contravención a un orden o norma moral constituye en último término un daño que sufre la sociedad en algún sentido. ${ }^{53}$

Como ya dijimos, nos interesa el moralismo en sentido estricto. Por tanto en último término nos interesará averiguar si esta forma de moralismo - que apela a una determinada norma u orden moral que señala como vulnerado - deviene o no en consecuencialista. Es decir, hemos de averiguar si la vulneración del orden o la norma moral merece reforzamiento jurídico-penal de modo intrínseco o por una reconducción en último término a la dañosidad social que puede producir la conducta.

Respecto del moralismo en el sentido amplio, su forma 'pura' recibe en la obra de Feinberg el nombre de 'conservadurismo'. ${ }^{54}$ Según esta corriente, el

\footnotetext{
${ }^{52}$ Feinberg, J., Harmless Wrongdoing, pp. 3 - 4.

${ }^{53}$ Feinberg, J., Op. Cit., p. 8.

${ }^{54}$ Ibid., pp. 39 y ss.
} 
reconocimiento de alguna acción que se constituya en causante de un cambio drástico en la 'forma de vida' (Way of life) de una sociedad (aunque el cambio sea paulatino y gradual) provee una razón suficiente para proceder a su tematización penal. El problema aquí está dado, naturalmente, por el mero recurso retórico que representa el concepto 'forma de vida', el cual carece en la tradición de las ciencias sociales de la elaboración y desarrollo de que gozan conceptos como 'cultura' y similares. ${ }^{55}$ Sin perder la 'pureza' del conservadurismo podemos afirmar que, de todos modos, existe un objeto de protección y está dado por la llamada 'forma de vida'. Cuando el objeto de protección se concretiza demasiado, según Feinberg, pierde su 'pureza' y deviene entonces en un 'conservadurismo impuro', reconduciendo el fundamento del reproche a ciertos valores concretos como la 'justicia como equidad' (fairness) ${ }^{56}$ o bien, se reconoce vulnerada la forma de vida que a través de su representación como mayoría en una sociedad ésta proclama como 'buena' o 'correcta. ${ }^{57}$

El moralista en sentido amplio 'impuro' equivale para Feinberg al perfeccionista legal. Aquél que pretende legislar para efectos de 'elevar el carácter' de los ciudadanos y hacer a éstos 'buenas personas'. Tiene razones para legislar que se considera la personalidad de los ciudadanos que conviven en una comunidad política determinada, más su objetivo es la evitación de cualquier tipo de 'mal' independiente del orden moral concreto que pudiere verse vulnerado. ${ }^{58}$

Respecto del moralismo en sentido estricto - apela a la validez de una norma moral con potencial correctivo - éste también reconoce una forma pura y una impura.

El moralismo en sentido estricto 'puro' no apela a nada más que a la moral. Un acto, ya sea se lleve a cabo en privado, entre adultos y que hubieren previamente consentido en ello, será apto para contravenir la norma moral si desobedece el mandato que contiene. No hay un interés en preservar los valores de una sociedad determinada ni nada por el estilo, sino simplemente el verdadero orden moral. La pregunta surge inmediatamente ¿Cuál es el 'verdadero' orden moral? Según Feinberg, la tarea de encontrar dicha referencia la debe asumir el moralista estricto puro, ${ }^{59} \mathrm{y}$ logrará su objetivo encontrando 'ejemplos relevantes' de actos que, desde su perspectiva, se presenten como candidatos aptos para producir lo que Feinberg denomina 'males flotantes'. ${ }^{60}$ Propone el autor adelantarse al discurso del moralista y buscar en actos como: filmes pornográficos, espectáculos

\footnotetext{
55 Ibid., p. 77.

${ }^{56}$ Ibid., pp. 50 y ss.

${ }^{57}$ Ibid., pp. 55 y ss.

58 Ibid., pp. 277 y ss.

59 Ibid., pp. $125-126$.

60 Traduzco como 'males flotantes' lo que para Feinberg son free-floating evils. Para una explicación de su naturaleza - básicamente son males de los cuales no se predica asociación alguna con una persona humana, es decir, escapan a la taxonomía de males que el mismo Feinberg ofrece en su obra - véase la nota 3 del capítulo 28 de Harmless Wrongdoing, y en particular pp. 17 y ss.
} 
públicos de nudismo, peleas de box, peleas callejeras promovidas por otros individuos, etc., potenciales candidatos para portar esta categoría. ${ }^{61}$ Interesante en este punto resulta la tarea de demarcar la diferencia que existe entre el disfrute privado (o como espectador que forma parte del público) de estos espectáculos (piénsese en el disfrute de una pelea de box o de un film gore o de una película pornográfica poco convencional en el hogar) por una parte, y la promoción de estos mismos por parte de la sociedad, lo que puede tener como resultado que la sociedad sufra un daño, causado por la promoción de estas actividades. ${ }^{62} \mathrm{La}$ pornografía infantil nos provee de un buen ejemplo para insistir en la importancia de la distinción. ${ }^{63}$

${ }^{61}$ Ibid., pp. 127 - 129.

${ }^{62}$ Llevar adelante esa compleja y fina distinción es la tarea que asume Feinberg en Ibíd., p. 132.

${ }^{63} \mathrm{Me}$ refiero a la tesis en virtud de la cual el fundamento de la punibilidad del mero almacenamiento de pornografía infantil (conducta materialmente desconectada del proceso de producción que presupone un atentado a la integridad sexual de los menores involucrados, y que se ejecuta como conducta en la esfera privada casi de modo paradigmático) descansa en el carácter problemático de aquél "mercado" donde se hace habitual la transacción y traslación del material pornográfico infantil (Véase Ost, S., Children at risk: Legal and societal perceptions of the potential threat that the possession of child pornography poses to society, Journal of Law and Society, Vol. 29, n³, 2002, pp. 451 453).Considero que esta tesis se topa con tres problemas esenciales, o debe al menos dar respuesta a tres interrogantes básicas: La primera cuestión es fenoménica y se refiere a la existencia concreta de un 'mercado' donde habitualmente ocurren transacciones de material pornográfico. Por 'mercado' entiendo al menos un espacio donde se transan bienes a cambio de dinero y se fija un precio en virtud de las leyes económicas de oferta, demanda y otras. La pregunta es fenoménica porque donde exista transacción, existirá el fenómeno de 'mercado' y aunque éste funcione fuera de la dimensión de lo tematizado jurídicamente, existirá como tal en la medida que un número determinado de sujetos intercambie bienes por dineros y fijen de ese modo un precio. El argumento que niega la existencia (ontológica) de ese mercado es un argumento de regulación legal, que es el siguiente: 'no puede existir un mercado allí donde todas las posibles formas de intercambio o traslación de cierto ‘bien’ están prohibidas'; y es éste el caso preciso del inciso primero del art. 374 bis del código penal chileno donde, utilizando la mayor cantidad de locuciones posibles se ha querido amenazar con una pena la posibilidad de traslación o transacción de material pornográfico infantil. Ahora bien, el papel que cumple la conducta meramente pasiva de almacenamiento resta como otro problema para esta tesis. Independientemente de la constatación ontológica de un mercado, el flujo de información (por ejemplo, a través de internet) de material pornográfico y pornografía infantil en particular exige una clarificación de la contribución que el acto de almacenamiento puede tener, no ya en la definición del mercado, sino que en la existencia de un flujo de información. Éste viene a ser el segundo problema de la tesis. Puede comenzarse desde ya destacando una cuestión que parece trivial: la agencia del sujeto almacenador es meramente pasiva, en este sentido la estructura típica del delito no puede corresponder a la de un delito de acción, sino más bien a uno de 'mera actividad'. En efecto, no se requiere de agencia positiva por parte del sujeto, sino meramente la mantención (pasiva) de un estado de cosas para la producción del hecho típico. Bien puede afirmarse que esta formulación de la estructura del tipo sólo es relevante allí donde el sujeto almacenador no es el mismo que el adquirente. En caso de que así sea, el requisito subjetivo del tipo sólo se verá satisfecho una vez que, observando el material que se ha visto accidentalmente almacenado en su sistema de almacenamiento de información, el sujeto no proceda a su destrucción inmediata. En el caso contrario, quien adquiere dolosamente también almacena dolosamente; de cualquier forma, la sucesiva corroboración temporal del acto de almacenamiento posterior a la adquisición, y la asociación que la norma penal hace de ambas 
Gallego - El problema del legalismo legal en el derecho penal

Por último, el moralismo en sentido estricto 'impuro' es probablemente el más célebre y el más controversial. Se trata de la llamada 'Tesis de la desintegración social' que se expone en The enforcement of morals ${ }^{64}$ de Patrick Devlin. ${ }^{65}$ Haremos referencia a esta tesis a lo largo del trabajo y en particular en la sección siguiente. Si algo podemos decir ahora sobre esto es lo siguiente: la base de la teoría de la desintegración social en la que descansa es su apelación constante a la analogía con la desintegración política por medio de la traición ${ }^{66}$ por un lado, y el estándar del hombre razonable por el otro. ${ }^{67}$ En todo caso, me parece que la analogía con la traición cumple el papel preciso de reforzar la dureza de la tesis en términos de defensa de una moral estricta, puesto que permite de este modo alcanzar (y abarcar especialmente) los actos inmorales ejecutados en privado. Es decir, el vínculo que se pretende es particularmente fuerte, alcanza así incluso a los casos en que las acciones llevadas adelante en la esfera privada de las personas, puesto que se postula a su respecto la aptitud para poner en cuestionamiento la integridad de la moral de una sociedad. La apelación que se hace es a nuestras intuiciones. Debemos pensar en el estado mental del agente que tiene la sensación de estar

conductas en cuanto a la descripción y quantum de pena, tornan irrelevante la acreditación de una u otra. Nótese sin embargo, que si volvemos a la cuestión de la ontología del mercado, y nos preocupamos en vez por la ontología del flujo de información, notaremos la verdadera naturaleza del segundo problema de esta tesis, y éste es subyacente tanto a la conducta de adquisición como de mero almacenamiento. Advertir el verdadero problema subyacente exige reconocer una diferencia entre la demanda de información que potencia la provisión de esa información y la mera adquisición de información que ya está disponible. Y es en este punto donde el ejemplo del almacenamiento de pornografía se torna relevante para nuestro análisis. Sólo en el primer caso la tesis es operativa como explicación (y como criterio de legitimación), en el segundo caso no lo es. Éste es precisamente uno de los problemas que trata Feinberg a propósito del disfrute de imágenes, videos y espectáculos considerados brutales u ofensivos. El punto de la distinción radica en notar que, en la medida en que la pretensión de disfrute de cada individuo considerado por separado al ser satisfecha contribuya a la generación de un mercado que provea de ese material o un flujo de información considerable, una norma penal que lo prohíba o censure descansará sobre un criterio legitimatorio consecuencialista, es decir, del tipo de 'moralismo impuro'. En cambio, en tanto sólo nos preocupe lo que pasa por la mente de un espectador individual cuyo goce o disfrute no contribuye en nada a la generación del mercado o al flujo de información, la norma que prohíba esa posibilidad de goce será moralista pura (estricta o devliniana). Véase Feinberg, Harmless Wrongdoing, p. 132.

${ }^{64}$ Devlin, P., The enforcement of morals, Oxford University Press, London, 1965. Fundamental para su comprensión el artículo publicado poco después del libro de Devlin, Dworkin, R., Lord Devlin and the Enforcement of Morals, The Yale Law Journal, Vol. 75, nº, 1966. Sobre el concepto de moralidad de Devlin véase Dybikowski, J.C., Lord Devlin's morality and its enforcement, Proceedings of the Aristotelian Society, New Series, Vol. 75 (1974 - 1975), pp. 89 - 109. Véase en general George, R.P., Making men moral, Oxford University Press, USA, 1995, pp. 48 - 51. Para una interpretación comunitarista de la tesis de la desintegración devliniana (a modo de una defensa de ésta) pp. 65 - 71 ${ }^{65}$ Feinberg, Harmless Wrongdoing, pp. 133 - 155. Incluye el debate con H.L.A. Hart al que nos referiremos más adelante. Algunas aplicaciones de este debate pueden verse también en Harm to Self, p. 265

${ }^{66}$ Devlin, Op. Cit., p. 13.

${ }^{67}$ Ibid., p. 15. 
haciendo algo incorrecto cuando, por ejemplo, almacena pornografía infantil y la "consume" desde la comodidad de su hogar. El individuo "traiciona" a la sociedad en que vive por cuanto no se comporta atendiendo a los estándares a que el resto de los individuos se somete. Se trata en algún sentido de la operatividad de un principio de universalización, por medio del cual se juzga la inviabilidad de un acto como proyecto de vida generalizable e universal por ser incompatible con la forma de vida de nuestra sociedad (o con la estructura política de nuestro Estado).

¿Cómo funciona la analogía? Cómo lo mostrábamos en el ejemplo del sujeto que despliega un razonamiento en solitario donde pretende generalizar su conducta privada. Así Devlin apela - como se comentaba más arriba - a un estándar abstracto evaluativo de la conducta concreta en la forma de una 'persona razonable' y compara, entonces, la acción concreta del agente culpable con aquello que la 'persona razonable' habría hecho en su lugar. ${ }^{68}$

Antes de seguir avanzando estimo necesario asumir un problema que de modo intuitivo enfrenta el moralista. La pregunta apunta a la posibilidad de que el moralismo haga referencia simplemente a un criterio de reconocimiento de acciones dañosas pero que afectan a los individuos de un modo menos intenso que el daño propiamente tal, en sentido milliano. Esta cuestión fue desarrollada por Harlon Dalton en una reseña al segundo volumen de la obra de Feinberg, que se dedica al así llamado principio de ofensividad. ${ }^{69}$ Por la estrecha relación que se propone existe entre ambos principios, merece aquel algún comentario.

Según Feinberg, la categoría de "ofensa" se localiza en el medio entre el daño y el moralismo. Dejando de lado el paternalismo como forma de intervención penal, desde el daño hasta el moralismo se postula la existencia de categorías descendientes de interacción lesiva con otros. Así, el daño es causado cuando la interacción entre dos individuos resulta lesiva en el máximo nivel posible, y cierta intervención penal será caracterizada como 'moralista' en cuanto la interacción (o actuación individual) carezca de lesividad en ese sentido. Cierta conducta será ofensiva entonces cuando "cause cierta perturbación en los sentidos, la sensibilidad moral, o la paz interior". ${ }^{70}$ Es de notar que la conducta no debe ser lesiva por cuanto debe excluir la categoría de 'daño' propiamente tal. ${ }^{71} L a$ pregunta relevante se refiere, por tanto, al umbral que separa la perturbación de la

\footnotetext{
${ }^{68}$ Feinberg, Harmless Wrongdoing pp. $136-137$

${ }^{69}$ Dalton, H.L., Review: "Disgust” and punishment, The Yale Law Journal, Vol. 96, nº4, 1987, pp. 881 913

70 Feinberg, J., Offense to others, pp. 14-22 (Tratamiento diferenciado de las formas de ofensa o perturbación). Asimismo Seher, G., Op. Cit., pp. $82-83$.

71 El lector no debe desorientarse en lo relativo al fundamento independiente del principio de ofensividad. Consciente de su precariedad, en todo caso, ofrece Feinberg una ilustrativa lista de estándares que deben verificarse de modo de reconocer la presencia de una ofensa relevante y que resulta asimismo útil para definir la procedencia en la dimensión legal del principio de proporcionalidad. Véase la lista en Feinberg, J., Offense to others, p. 35
} 
sensibilidad moral (en la forma de una ofensa), y la perturbación de un orden moral (en la forma de una aproximación moralista).

Antes de tratar dicha distinción quisiera destacar lo siguiente. En la obra de Feinberg, enteramente dedicada a tratar las meras perturbaciones como forma de agencia prohibida penalmente, parte importante lo ocupa la pornografía ${ }^{72}$, y la exhibición de la misma, entendida como una práctica que 'ofende' la sensibilidad de las personas, y cuyo manejo entonces, debe estar tematizado jurídicopenalmente (o al menos debe estar regulado). Respecto a la pornografía, antes de referirse a ésta desde toda perspectiva posible, Feinberg destaca que un modo de producir una perturbación no lesiva en otro sujeto es mediante un acto que altere su sistema nervioso vegetativo, es decir, mediante un acto que le produzca 'asco' o 'repulsión'. Ésta forma de perturbación se reconoce con el uso del predicado 'obsceno' que se adjudica a ciertas acciones o actos de habla, y que ofenden a su receptor. ${ }^{73} \mathrm{El}$ uso del adjetivo 'obsceno' puede hacer referencia al estado de ánimo íntimo que la acción o acto de habla produce en el receptor, o bien a posibles reacciones (de condena y desaprobación) que el hablante adelanta al denotar con este concepto al objeto, refiriéndose a puntos de vista externos y no ya internos. ${ }^{74}$ Luego prosigue Feinberg destacando los orígenes de lo 'obsceno' en lo 'vulgar' y desarrolla un tratamiento de la vulgaridad como criterio evaluativo utilizado por la sociedad. ${ }^{75}$ En cualquier caso, desde experiencias sensoriales o culturales menos inmediatas, Feinberg procede a identificar el concepto con experiencias mucho más inmediatas, y así termina localizando el origen de la obscenidad ( $y$ por ende de la ofensa en este sentido) finalmente en el 'asco' como experiencia sensorial (yukkines). ${ }^{76}$ Lo que a nosotros nos interesa es lo que sigue a continuación: el tratamiento de la pornografía como una forma de expresión 'obscena' y perturbadora.

Creo que lo central para tratar la relación no es preguntarse - como lo hace Feinberg al comienzo - si es posible considerar la pornografía como una expresión o manifestación artística y por lo tanto excluida de la categoría de lo obsceno, ${ }^{77}$ sino más bien - y esto prescindiendo por completo, al menos en principio, de una conceptualización de 'lo pornográfico'- si cualquier expresión de la sexualidad debe considerarse obscena o perturbadora. La respuesta intuitiva - y sintomática del carácter cultural (en el sentido freudiano) que tiene la cuestión - a esa pregunta es la siguiente: 'la expresión de sexualidad será obscena y perturbadora en tanto sea pública'. Esto en nuestro idioma se conoce como pudor, y muy evidente resulta que el objeto de protección - por ejemplo - de la norma penal del art. 373 reconozca

\footnotetext{
$72 \mathrm{Al}$ menos dos capítulos completos en Offense to others,. pp. 127 - 189.

73 Ibid., p. 97.

74 Ésta última en Ibid., p. 103.

${ }^{75}$ Ibid., pp. 107 y ss.

${ }^{76}$ Ibid., pp. 112 y ss.

77 Ibid., pp. 129 - 138. De particular interés (para quien se interese en la cuestión) resulta el análisis del controversial filme 'Emmanuelle' y su caracterización como pornografía, p. 133.
} 
como objeto de protección 'el pudor y las buenas costumbres'. Según Feinberg, para desenmascarar al pudor como objeto de protección o al menos como objeto relevante de una discusión es necesario distinguir nuestra aproximación referencial a dos hechos distintos: los actos propiamente sexuales por un lado, y la exhibición de dichos actos sexuales. Respecto de los primeros, es probable que los estándares convencionales básicos excluyan ciertas conductas del merecimiento de aprobación social, como es el caso del sexo fuera del matrimonio o del sexo en lugares y momentos inapropiados; sin embargo, la desaprobación social se dirige de modo intenso a aquellas conductas que sólo se limitan a la exhibición de dichos actos y a la demostración pública de su naturaleza con absoluta normalidad. ${ }^{78}$ Aquí juega su papel un estándar de moralidad muy especial, pues se trata (en lo que alcanzo a ver) de un estándar de moralidad instrumental, que sirve a la revelación de la perturbación social que el acto de la exhibición del material sexual provoca. Es decir, quien en su experiencia sensorial se siente moralmente afectado por la libertad con que otros exhiben sus comportamientos sexuales, procede en un estadio ulterior a solidarizar con sus semejantes quienes refuerzan la validez de la convención social que desaprueba de modo categórico el acto aquél que en un primer momento provocó únicamente la afectación de la sensibilidad moral subjetiva. $^{79}$

Si se pone atención en la tesis, descansa primordialmente en la atención puesta a los estados de ánimo, los cuales se exteriorizan y de modo referencial sirven al reforzamiento de convenciones respecto de la vigencia de valores y normas de comportamiento respecto de lo que se predica en último término 'ofensivo'. Existe sin embargo una segunda aproximación a la cuestión que no descansa en ninguna apelación a la sensibilidad moral en este sentido específico, sino más bien al sentimiento de intimidad, profundamente vinculado al de privacidad, el cual se vulnera cuando se hacen manifestaciones explícitas o públicas de aquellos actos que se consideran por cualquier persona razonable 'íntimos, ${ }^{80} \mathrm{La}$ diferencia que esta segunda tesis hace respecto de la primera aproximación, es que exige para que el interlocutor valide su participación en el discurso, que sienta efectivamente repulsión al ver su esfera de privacidad vulnerada. En el caso anterior resulta ser más bien la experiencia de libre manifestación de lo privado por parte de terceros lo que disgusta al interlocutor, aún cuando nunca crea que él pueda verse directamente involucrado en una situación como esa. En este segundo caso, lo esencial es la postura de 'toma de distancia ${ }^{81}$ que caracteriza a los agentes cuando interactúan con otros y creen que podrían vulnerar su esfera de privacidad o intimidad, y la ruptura de esa distancia que genera la sensación de disgusto o rechazo. El ejemplo que cita Feinberg es el de la práctica de comer. Si bien es cierto que alrededor del acto de comer (por ejemplo, sentados en una mesa) no hay demasiadas reglas o tabúes, no es menos cierto que nos resulta particularmente

\footnotetext{
${ }^{78}$ Ibid., p. 139.

${ }^{79}$ Ibid., p. 140.

80 Ibidem (Párrafo segundo)

${ }^{81}$ Ibid., p. 141.
} 
desagradable estar cerca de otros cuando comen o que éstos se acerquen cuando comemos. Según el autor que cita Feinberg a este respecto, esta sensación es sintomática de la ruptura de la necesaria toma de distancia que causa desagrado. La misma explicación permite hablar de ofensas (como categoría penal) en el caso de la pornografía como representación explícita de actos íntimos, en este caso, sexuales.

A pesar de la plausibilidad de la tesis, la categoría de ofensa y su correlación con el principio de proporcionalidad en el nivel de determinación legal de las penas, denota una valoración todavía ínfima del verdadero daño que las conductas catalogadas como tales son capaces de producir en la sociedad. ${ }^{82}$ En este punto sostengo - radica la importancia (no siempre notada) de definir el umbral de la publicidad de la conducta como criterio de identificación del fundamento de legitimidad de una norma penal, siendo las opciones por lo general: principio de ofensividad o bien moralismo. El mismo Feinberg, al discutir el moralismo impuro de Devlin, considera que la forma más extrema de aplicación del juicio de contrastación hipotética del que se vale Devlin debe terminar por aceptar invasiones a la privacidad por parte del aparato punitivo estatal, en base -al menosa un criterio de justificación de la pena radicalmente prevencionista. ${ }^{83} \mathrm{De}$ este modo, la paradoja utilitarista de la pena justifica intervenciones extremas en las actividades privadas de los individuos, de modo tal que se permita con ello satisfacer el mandato del juicio de contrastación hipotético devliniano. Considero que ulteriores diferenciaciones a este respecto se hacen innecesarias, pues en los textos las categorías se revelan como insuficientes en la medida en que no se apoyen en ejemplos concretos. Sobre esto Harlon Dalton ha señalado precisamente a Devlin como el teórico que hace explícito el vínculo en la dimensión teórica entre el objeto del principio de ofensividad y del moralismo (porque Devlin menciona explícitamente la palabra disgust para referirse a aquello que la sociedad no debería tolerar, y que además se sustenta sobre la base de la ley moral) ${ }^{84} \mathrm{La}$ cuestión del vínculo es interesante, pues nos plantea directamente el problema de la capacidad de rendimiento del estándar abstracto del hombre razonable devliniano, que parece - a la luz del comentario de Dalton - ahora exigir de nosotros que apliquemos un estándar de ofensividad, y tomemos el resultado como una toma de postura respecto de cierta concepción de la moral, primero, y del rol que cumple en la sociedad, en relación al derecho. Si, en todo caso, fuera ésta precisamente la operación que llevamos adelante al preguntarnos por nuestros valores morales, entonces los liberales tienen que superar su moral arguphobia (en términos de Husak) y adentrarse todavía más en la concepción de la moral que

\footnotetext{
82 Así, en nuestro derecho las ofensas al pudor por un lado y la conducta que quebranta las reglas de decencia son ambas relegadas a las faltas (art. $495 \mathrm{n}^{\circ} 5$ y $496 \mathrm{n}^{\circ} 9$ respectivamente).

${ }^{83}$ Feinberg, J., Harmless Wrongdoing, p. 140.

${ }^{84}$ Dalton, Op.Cit., p. 907.
} 
manejan al hacer frente al moralismo legal (en cualquiera de sus cuatro formas). A ese problema me dedico a continuación. ${ }^{85}$

${ }^{85}$ Dejé pendiente un análisis crítico concreto sobre la base del principio del moralismo. Los fallos de la Corte Suprema norteamericana sobre sodomía constituyen una instancia perfecta para ello, pues cumple el papel además de servir de contraste con los argumentos expuestos en el fallo del Tribunal constitucional chileno comentado. Me dedico a ello en esta nota al pie: Tanto en el voto de mayoría en Bowers como en el argumento de Scalia en Lawrence (aún no comentado) se aprecia una aproximación compartida al fenómeno de la punición de prácticas sexuales privadas: Resulta irrelevante el hecho de que la práctica sexual sodomítica consentida entre personas del mismo sexo y realizada en privado no cause daño a ninguno de los participantes ni tampoco a terceros no involucrados en ella (la práctica es privada); hay algo que está simplemente mal en dichos actos. Esto sugiere que la punibilidad debe mantenerse y resulta además coherente con una interpretación histórica de la opinión cultural mayoritaria hacia la realización de dichas prácticas. Las diversas razones que puedan darse (históricas, culturales, etc.) para fundamentar la punibilidad permiten precisamente reconocer la variación del argumento, pero en lo que debemos estar de acuerdo (o más bien, en lo que conservadores como Scalia deberían estar de acuerdo) es en la premisa inicial del argumento: hay algo que está mal en la realización de dichas prácticas y alguna entidad, principio o valor resulta vulnerado con su ejecución. En su versión simple, la justificación de la punibilidad de un acto sexual privado constituye un ejemplo de 'moralismo' tal y como aquí se lo ha presentado. Respecto del argumento conservador en Bowers relativo a la inexistencia de un 'derecho a la sodomía' que se derive de una interpretación amplia de la enmienda constitucional que proclama la igualdad de libertad de los ciudadanos, en principio no se trata de un argumento crítico o una propuesta relativa a la dimensión de tematización jurídico-penal. Se trata de un argumento constitucional. Es un argumento relativo a la eventual colisión entre derechos subjetivos y la manera en que dicha colisión puede resolverse (a través de un juicio de ponderación) o bien evitarse; camino este último el que sigue la opinión conservadora en el fallo. Por esta razón, quisiera dejar en suspenso el argumento sobre el 'derecho a la privacidad', o a 'ser dejado en paz', o a la libertad en sentido amplio, o al ejercicio de prácticas sodomíticas en sentido restringido - o como quiera interpretárselo - para poner la atención en el segundo argumento conservador relativo al rechazo a la disidencia moral como base razonable para una decisión judicial. Si este rechazo fuese apto al mismo tiempo para señalar el mal cuya evitación pretende la norma penal, entonces calificaría (de modo muy estrecho) como moralismo 'puro' al menos. Sostengo que ello es así porque un argumento que apela a la autoridad del derecho evitando la reconducción del criterio de validez a una regla de validez independiente, o a principios morales independientes, y que al mismo tiempo defiende una norma cuyo objeto resiste la introducción de modo intenso de un criterio de corrección normativa moral, es un argumento que sostiene la inmoralidad inherente del objeto de referencia de la norma en cuestión. Ahora bien, este punto no puede ser inocente, sobretodo considerando que esconde una aparente contradicción lógica: No se puede afirmar que el criterio de corrección que permite la calificar de 'inmoral' una conducta tiene aplicación allí donde la autoridad del derecho no apela a una regla de validez independiente o a principios morales (esto se deriva en parte de Raz, J., Authority, Law and Morality, en 'Ethics in the Public Domain: Essays in the Morality of Law and Politics, 1995; Aunque el punto debe incorporar algún otro razonamiento, pues en caso contrario se deja en un muy precario estado tanto a la tesis de la coherencia como a la tesis de la incorporación). Respecto del argumento histórico del Juez Burger relativo a la punibilidad de la conducta homosexual en general como reflejo de una cultura marcada históricamente por un rechazo a la expresión de dicha orientación sexual (que se introduce sin considerar el hecho de que, como se aprecia en las opiniones de los jueces liberales, existen buenas razones para dudar de la seriedad de dicha postura cultural mayoritaria, sobretodo atendiendo a las fuentes disponibles, como por ejemplo, la cantidad de denuncias y condenas. Véase la opinión de Kennedy en 539 U.S. 558 (2003), p. 568) ciertamente se trata de un argumento conservador, por el 
Gallego - El problema del legalismo legal en el derecho penal

hecho de que apela a la rectitud de la postura de desaprobación como medio para preservar a través de la amenaza penal, una determinada 'forma de vida'. Según Feinberg, el conservadurismo no es propiamente una categoría de moralismo, esto porque la postura conservadora (en la lógica de preservación de una forma de vida) admite diversas categorías (Así, conservadurismo puro e impuro, estricto o amplio. Lo que muestra que he usado en esta cita el adjetivo erróneamente), más lo que constituye el núcleo de la operatividad del argumento sobre la forma de vida es la idea del cambio cultural visto como un mal en sí mismo. Según Feinberg, en este punto queda anclado el argumento conservador como en un callejón sin salida. Para el conservador, ya sea puro o impuro (es decir, ya sea que crea en la inmoralidad ontológica o no) debe constituir una premisa básica de trabajo el que el cambio cultural constituya un mal en sí mismo (aunque de una extraña naturaleza). El hecho de que, para Feinberg, éste sea el último bastión del conservadurismo se explica por el reconocimiento al que el conservador se ve obligado, cual es, el de una esfera privada en la que la falta de publicidad de la acción sumada a la ausencia de daño a terceros por parte de la misma, torna precario el argumento que pretende reconocer un atentado a cualquier entidad, abstracta o concreta. El conservador puede y debe aceptar que esto es así pero con la condición de preservar como argumento la demostración mediante el uso de un ejemplo, que existen casos en que la actividad privada es dañina, y que en un ejercicio de ponderación, el derecho a la privacidad cede o debe ceder ante el ideal de evitación de daño a otros (Así Feinberg, J., Harmless Wrongdoing, p. 71). Aquí la pretendida pureza del moralismo conservador deviene en impura, cuando sólo puede apelar al consecuencialismo para demostrar que el objeto de protección de la norma penal lo constituye en último término la vida humana, en el sentido de la vida de todos los miembros de la sociedad. Por esta razón, lo que el conservador intenta evitar en realidad es la extinción biológica de la especie o un genocidio (en los ejemplos de Feinberg). Y en algún sentido, el racionalismo naturalista (por ejemplo) está más que dispuesto a impurificar su conservadurismo a través de dicha apelación al valor de la vida. El argumento de ellos será: Una masificación de la práctica sexual sodomítica traerá como consecuencia la extinción paulatina de la especie por medio del desuso de los mecanismos reproductivos. Es decir, la extinción biológica como mal es la consecuencia de la suspensión del acto sexual reproductivo. En este punto es necesario admitir lo improbable que resulta el hecho de que el mismo Juez Burger hubiera pensado en incluir una apelación a la impureza del racionalismo naturalista en su argumento. Y ello tiene que ver con el hecho de que una apelación histórica a la conservación de una 'forma de vida' no implica necesariamente, y en la mayoría de los casos es así, un consecuencialismo. Ahora bien, ello no obsta al hecho de que la apelación conservadora al pasado y el temor a la manifestación del cambio cultural (como mal) permita otra aproximación: la del temor a la publicitación de un acto sexual que pueda 'ofender' a otros y entonces afectar la sensibilidad de la sociedad. Es decir, un conservador bien puede pensar que el acto sexual sodomítico debe preservar su calidad de tabú. Con esto volvemos al problema de la problemática distinción entre moralismo y ofensividad (véase supra nota 69). Me parece que esta aproximación sólo tiene como consecuencia debilitar el espacio de discusión en torno a la calificación de 'inmoral' que reciben los así llamados 'delitos sexuales de mera inmoralidad'. El efecto de debilitamiento de dicho espacio de discusión es la consecuencia de creer que el problema del ejercicio privado del 'coito desviado' es un problema de publicidad de la desviación, así como la masturbación podría serlo desde que califica como candidato para 'mal flotante' o 'mal en sí mismo' desde el punto de vista conservador impuro. Ahora bien, respecto del argumento central del Juez Scalia para disentir en Lawrence, relativo a la mejor versión del concepto de 'libertad' que se sigue de la enmienda constitucional (Véase a este respecto la descripción de Vial, Op. Cit., p. 245), éste argumenta que el concepto de libertad no puede ni debe ser interpretado de modo tan amplio; tan amplio quiere decir, que permita la deducción de un derecho derivado del cual sean titulares los homosexuales y les permita involucrarse en actos sexuales sodomíticos. Aunque la cuestión no es tan clara, sí puede derivarse parte de esta disputa del intento de Scalia de responder negativamente a la tercera pregunta que Kennedy se formulara: ¿Debe ser invalidado el precedente de Bowers? Para 
Scalia, la invalidación de dicha decisión importaría invalidar Roe v. Wade (central para sustentar el derecho derivado a la privacidad) asimismo, y así una seguidilla de desconocimientos de restricciones razonables a la libertad traerían como consecuencias devastadoras (no puede ser más explícito Scalia: "What a massive disruption of the current social order, therefore, the overruling of Bowers entails." 539 U.S. 558 (2003), p. 591). Del mismo modo en que la apelación a la tradición histórica de Burger ésta no es una reclamación directamente 'moralista'; y así como la discusión de White sobre la existencia o no de un 'derecho a la sodomía' ésta es más bien una cuestión de ponderación. La pregunta es: ¿Ponderación respecto a qué? Digamos que si Scalia pudiera apuntar la razón por la cual considera que la existencia de un derecho a la sodomía (lo que se sigue de entender que la libertad negativa de los homosexuales incluye ciertamente el acto sexual) constituye un mal, la naturaleza de dicha razón nos permitiría descubrir la clase de moralismo que se esconde detrás de su reclamación. De este modo, tildarlo de 'conservador' (por asimilar el cambio cultural con los males que flotan como cánceres que corroen el espíritu de la sociedad) nos permitiría iniciar la ronda de preguntas que terminarían - como ya sabemos - con su acorralamiento y la búsqueda entonces de la única respuesta disponible: consecuencialismo reaccionario (tal y como ocurrió con Burger más arriba). Si esto fuera así, cabe aceptar que algún momento de reflexión le cabría conceder al conservador, para efectos de proceder a su juicio de ponderación: entre el mal que supone el ejercicio de una libertad versus el bien que le hace a la sociedad la neutralización de dicha libertad. Ahora bien, todavía más interesante me parece la apelación que hace Scalia a la tematización jurídico-penal histórica del acto sexual sodomítico, donde la pregunta por la orientación sexual de quienes practican dichos actos resulta irrelevante para el análisis de lo que es importante (539 U.S. 558 (2003), p. 596. Es una cita a la opinión de mayoría en Bowers donde se asienta la idea. Afirma Scalia: "It is (as Bowers recognized) entirely irrelevant whether the laws in our long national tradition criminalizing homosexual sodomy were 'directed at homosexual conduct as a distinct matter'....) the only relevant point is that it was criminalized - which suffices to establish that homosexual sodomy is not a right 'deeply rooted in our Nation's history and tradition"). Este argumento se complementa con la apelación a las antiguas raíces de la prohibición de la sodomía, para concluir que la norma penal refuerza una desaprobación cultural general hacia toda forma de coito desviado, y no tiene como consecuencia ningún efecto discriminatorio (en el sentido de una vulneración al principio fundamental de igualdad) respecto de los homosexuales. Lo que es claro de esta postura, es que es al menos 'pura', en el sentido de que la desaprobación que produce la desviación del acto sexual coital responde a la contravención de un orden moral natural; pudiendo ser, por tanto, amplia (conservadurismo) o estricta (condena la inmoralidad). De cualquier modo, se trata de un modelo pre-ilustrado, que condena la desviación del acto sexual para honrar así un determinado orden natural. Como sabemos, dicho modelo pre-ilustrado se caracterizó del mismo modo, por no hacer distinciones entre las distintas formas de orientación sexual de los participantes. Tanto así, que en el caso de participar de modo consentido la mujer en un acto sexual de penetración anal se la consideraba partícipe en el sentido jurídico-penal. Importan aquí las distintas formas de sodomía que eran abiertamente condenadas por el modelo pre-ilustrado, puesto que todas ellas caben en la disposición normativa-penal que defiende Scalia como enraizada en la tradición norteamericana. Así, incluiría dentro de la sodomía llamada 'propia' (sostengo que excluye la sodomía impropia que hace referencia a actos sexuales en solitario o donde no participa otro ser vivo como la masturbación o la penetración de algún objeto con alguna protuberancia del cuerpo) la llamada sodomía por razón de genero (acciones homosexuales tanto masculinas como femeninas, ergo incluiría comportamiento lésbico) y por razón del orden natural (coito anal y cualquier acción sexual que no consista en la colocación del pene en la cavidad vaginal con fines reproductivos, el llamado 'sexo reproductivo'). Respecto a la apelación al fundamento racional de la norma que hace Scalia, que termina asociando al fundamento 'moral' de la prohibición de relaciones sexuales sodomíticas ${ }^{85}$ ciertamente califica como moralismo puro en sentido abstracto (respecto del cual se desconoce su tendencia concreta sin tener mayor información), y me parece que no merece mayor 


\section{4. ...COMO UNA OPORTUNIDAD PARA VOLVER A LA DISCUSIÓN SOBRE LA SEPARACIÓN ENTRE DERECHO Y MORAL}

Quisiera volver a mirar ciertos aspectos a veces olvidados de la muy conocida discusión en torno a la distinción entre derecho y la moral y la pregunta por la legitimidad del reforzamiento de la segunda dimensión de regulación del comportamiento por parte de la primera. La premisa de trabajo será - por lo pronto - que las prácticas sexuales - como por ejemplo, sodomía consentida entre individuos del mismo sexo o almacenamiento de pornografía infantil - ejecutadas en privado, corresponden a una dimensión del comportamiento que admite, al menos, un juicio moral de aprobación o desaprobación. Sin embargo, ello no asegura que se haga operativo un criterio de corrección normativa respecto del mismo comportamiento, a menos claro que se piense que la institucionalización de cierto rechazo generalizado hacia cierto comportamiento es razón suficiente para conceder que un juicio sobre admisibilidad moral es igualmente competente. Esto último es precisamente lo que pretende resolver el debate sobre el reforzamiento de la moral por medio del derecho. Es un debate que, por tanto, no tiene siempre asegurado el camino que recorre la transitividad moral hacia los principios fundantes de nuestra común racionalidad humana.

El punto de partida obligado en esta discusión debe estar en Kant. Como se sabe, la filosofía del derecho de Kant está construida como un sistema que es en gran parte (o al menos bajo alguna interpretación razonable) independiente de su teoría sobre el razonamiento práctico en contextos no institucionalizados. El fundamento del derecho en Kant es la protección de la libertad, y la posibilidad del ejercicio de la libertad de cada individuo limitada por la libertad de otro. Como se sabe, Kant distinguía entre el ejercicio de libertad externa, que cae en la esfera o alcance del derecho como sistema o dimensión de regulación del comportamiento, por un lado, y el ejercicio de la libertad interna, irrelevante para el derecho. No es, sin embargo, sino hasta el desarrollo de la doctrina de la virtud que Kant desarrolla la necesidad de justificación de la agencia que se fundamenta en el cumplimiento del deber, y la necesidad a su vez de una calificación de la rectitud de un comportamiento conforme a deber. De la característica propia de un actuar virtuoso se sigue el siguiente corolario: las razones para seguir el derecho, en tanto

comentario. Respecto del argumento consecuencialista de Scalia, esto es, la idea de que al remover la desaprobación moral como fundamento de la punición de la sodomía, se dejará en un vacío insoslayable a otras instituciones sociales reguladas por el Derecho, como el matrimonio heterosexual (539 U.S. 558 (2003), p. 589), me parece que aquí se halla el germen de una arremetida fuerte del moralismo impuro. En efecto, cuando se pasa de apelar al respeto por las tradiciones al sostenimiento del sistema de instituciones de la sociedad presente se pasa de la pureza a la 'impureza' propia de la 'desintegración social' de Devlin respecto de la cual tan cerca se encuentra esta última interpretación del argumento de Scalia. Espero que esta revisión de alguno de los argumentos relevantes de estos dos célebres fallos a la luz de las categorías del moralismo sean de utilidad e insten a un contraste posterior con las construcciones argumentativas que se observan en el fallo de nuestro Tribunal Constitucional. 
afectan el ejercicio de la llamada libertad externa, vinculan al individuo sin importar la convicción que éste se haya formado respecto al valor de su acción conforme al deber jurídico (libertad interna). Hoy podemos afirmar con seguridad que el desarrollo más acabado de esta perspectiva se encuentra en el así llamado 'mandato de neutralidad del derecho'.

Ahora bien, a pesar de ser éste el punto de partida, no puede afirmarse de modo concluyente que nuestra comprensión del mandato de neutralidad del derecho haya sido siempre pacífica, en el sentido de observar al derecho occidental como un conjunto de reglas cuyo contenido debe ser 'neutral' respecto de las convicciones morales de la comunidad determinada cuyo comportamiento pretende regular. Lo que sí es claro es que el espacio de la discusión encuentra un punto de inflexión en la segunda mitad del siglo XX en la reflexividad que comenzó a operar en el derecho entendido propiamente como un sistema de reglas. Esta reflexividad se caracterizó por ser un presupuesto de cualquier discusión sobre el derecho y la operatividad del mandato de neutralidad. Lo curioso de dicha reflexividad interna - estoy haciendo referencia al positivismo jurídico hartiano - es que su artífice, H.L.A. Hart, era antes que un (gran) teórico del derecho, un gran conocedor del importante papel que el constructivismo sociológico - por ejemplo, el que hoy atribuimos a Peter Berger y Thomas Luckmann - jugaba en nuestra comprensión del fenómeno de seguir una regla. Esto explica, naturalmente, su particular obsesión por marcar los deslindes entre la moral como sistema de reglas, y el derecho como sistema reflexivo de reglas, atribuciones de autonomía y sanciones. Esto se aprecia en El concepto de Derecho, donde afirma Hart que "Estas frases [la moral convencional o de una sociedad] aluden a pautas o criterios de conducta que son ampliamente compartidos en una particular sociedad, y que deben ser contrapuestos a los principios o ideas morales que pueden regir la vida de un individuo, pero que éste no comparte con ningún número considerable de aquellos con quienes convive". ${ }^{87}$ Luego habría de asociar Hart las reglas morales con las así llamadas 'reglas primarias' en el sentido de que comparten con éstas la propiedad de operatividad deóntica y permiten entonces la regulación del comportamiento de los miembros de una sociedad de modo independiente a la dimensión de las normas jurídicas hasta que la complejidad de la sociedad torna necesaria la elaboración de un sistema jurídico en sentido estricto compuesto por reglas secundarias. Es en este momento, según Hart, cuando la moral (en tanto conjunto de reglas) refleja la identidad de una comunidad particular, en el sentido de reconocer la atribución de funciones simbólicas a ciertos actos en la forma de reglas primarias consistentes. ${ }^{88}$

\footnotetext{
86 Véase Kindhäuser, U., La fidelidad al derecho como categoría de la culpabilidad, en Kindhäuser y Mañalich, 'Pena y culpabilidad en el Estado democrático de derecho, Ara, Lima, 2009, p. 78. Postulando el vínculo esencial entre mandato de neutralidad y bases para la operatividad del principio de culpabilidad material, a partir de Kant.

${ }^{87}$ Hart, H.L.A., El concepto de Derecho, p. 210. Respecto a la distinción entre reglas y valores algo se dirá más adelante.

88 Ibid., p. 213.
} 
Como decíamos, Hart es consciente de que el derecho en gran sentido surge del reconocimiento de la importancia que la sociedad le atribuye a ciertas prácticas que a su interior se ejecutan. Por esta razón vuelve sobre esta consideración en el capítulo final de su obra fundamental, recordándonos la importancia del modelo hipotético de una sociedad regida por reglas primarias (morales) que adopta con posterioridad la institución del derecho (reglas secundarias). A este respecto, destaca las bondades pero también los riesgos que se corren con dicho proceso de institucionalización. La respuesta a uno de esos riesgos - el uso del aparato jurídico para la opresión de muchos - es precisamente el resurgimiento de la idea de que el derecho necesita adecuarse en algún sentido a la moral. Asimismo, concede Hart que los principios de la moral influyen notablemente en el proceso legislativo de producción de normas jurídicas, en una tensión incesante dada por la pretensión de la moral de adecuar el derecho a sus preceptos. $^{89}$

Como se aprecia, son éstas dos dimensiones muy distintas de la cuestión de la relación entre derecho y moral: una es la constante pretensión de adecuación como argumento para resolver los problemas que la institucionalización trae consigo y de los que se salva una sociedad gobernada únicamente por la reglas primarias; la otra es la del contenido moral de ciertas normas jurídicas que prohíben o mandan ciertos actos.

Neil MacCormick intentó precisamente trazar una distinción similar, entre el reforzamiento de la moral por parte del derecho (normas con contenido 'moralizante') por un lado, y moralismo legal, como una doctrina que debía ser combatida sobre la base del principio kantiano de neutralidad del derecho, por el otro. $^{90}$

MacCormick se propone encontrar un ámbito en el que la pretensión de regulación tanto de la moral como del derecho encuentre un punto muerto, que revele de ese modo la supremacía del principio de autoridad del derecho descargado de una fundamentación moral del ideal de autoridad y gobierno. Cree encontrarlo en el ideal de libertad de conciencia. ${ }^{91}$

Desde ya, hace mucho sentido la idea de que la libertad de conciencia constituye un importante valor moral y un ingrediente esencial de toda democracia. Sin embargo ¿Cuáles son las razones para justificar el dominio del derecho en el ámbito de la libertad de conciencia? Sobre esto hay dos comentarios que hacer a modo de desarrollo de la tesis. El primero es relativo a la pretensión general de MacCormick en términos de desarrollar una teoría del derecho. Se trata

\footnotetext{
${ }^{89}$ Ibid., pp. 249 - 252.

${ }^{90}$ MacCormick, N., A moralistic case for a-moralistic Law, Valparaiso University Law Review, Vol. 20, $\mathrm{n}^{\circ} 1,1985$.

${ }^{91}$ Ibid., p. 12.
} 
ciertamente de presentar una teoría positivista, continuando la tradición del positivismo reflexivo fundada por H.L.A Hart. ${ }^{92}$ Como sabemos, una teoría tal se encuentra recurrentemente con el problema de la intromisión de fundamentos morales en la cuestión de la obligación jurídica. La resolución que suele intentarse fluye a través de la necesidad de una separación sin reservas entre la moral y el derecho como sistema de regulación del comportamiento. Precisamente en este punto, MacCormick se enfrenta a 'la paradoja' de la relación entre derecho y moral, ${ }^{93}$ y se refiere fundamentalmente a la naturaleza moral de las razones que se dan para favorecer el soporte político o la reconducción al paradigma democrático del fundamento de la sujeción al derecho. El segundo comentario dice relación con el modo de solución de la paradoja. Curiosamente, MacCormick concluye que resulta poco deseable evitar la paradoja mediante un encierro del derecho en un lugar alejado de cualquier influencia de la moral. Ese lugar no existe. En vez, debe encerrarse a la moral para que quede en el lugar donde pertenece, alejada del derecho. ${ }^{94}$ Ahora bien, esto no supone reducir el ámbito de influencia de la moral, sino todo lo contrario. $\mathrm{Y}$ en esto radica lo interesante del punto de vista de MacCormick y su apelación al valor moral del ejercicio de la libertad de conciencia. Según MacCormick, hay que diferenciar la vulneración de la libertad de conciencia como externalidad negativa que puede ser provocada por una gran variedad de intromisiones del derecho en ámbitos de la vida social (como por ejemplo, por un determinado sistema de salud público), de una vulneración directa, provocada por el contenido 'moralizante' de cierta norma jurídica. En este caso se encuentra la tematización penal de conductas homosexuales consentidas privadas. ${ }^{95}$ Así, resalta MacCormick dos valores morales cuyo desarrollo libre el derecho debe permitir: la autonomía, ${ }^{96}$ la tolerancia. ${ }^{97}$

Respecto de la tolerancia, Joseph Raz la ha definido como el estado de continencia del deseo de dañar a otro, cuando se cree que el daño es merecido (por portar el otro, por ejemplo, una característica que lo diferencia de uno). ${ }^{98}$ Ésta

\footnotetext{
92 Ibid., p. 7.

${ }^{93}$ Ibid., p.3

94 A esta conclusión llega MacCormick gracias a una analogía con la relación entre la Política y la Religión a propósito de la historia relatada por M. Howe en 'The Garden and the wilderness'. La pregunta era si resulta más apropiado construir un muro alrededor de la religión o alrededor de la política. Veáse Ibíd., p. 11.

95 Ibid., p. 12.

${ }^{96}$ Ibidem., Interesante resulta contrastar el modo particular de argumentar que utiliza MacCormick, con la persuasiva retórica de los autores del Freakeconomics. En la introducción de dicho libro, los autores relatan un caso (real o hipotético) en el que en un estado determinado se reguló por ley una bonificación debida por el Estado a todo donante voluntario de sangre. Un análisis estadístico demostró que el número de donantes disminuyó drásticamente luego de hacerse pública la ley. La razón de ello era que la bonificación, lejos de representar un incentivo, se tornaba en un desincentivo porque al adjuntar una contraprestación a un acto desinteresado, éste perdía su carácter auténticamente moral.

${ }^{97}$ Ibid., p. 14.

${ }_{98} \mathrm{Raz}, \mathrm{J} .$, Autonomy, Toleration and the Harm Principle, en Ruth Gavison (ed.), 'Issues in Contemporary Legal Philosophy. The influence of H.L.A Hart’, Clarendon Press, Oxford, 1992, p. 320.
} 
concepción amplia excluye una visión estrecha de la causa del deseo de dañar a otro, comprometida simplemente con la conformación de la acción a un estándar moral que prohíbe dañar a otros.

Raz traza en su artículo una línea que vincula al principio de autonomía con la tolerancia y el ideal moral de una sociedad pluralista. En este marco se pregunta ¿Es posible o legítimo forzar a otro a encontrar su autonomía? Como sabemos, I. Berlin se habría preguntado lo mismo al postular su conocida distinción entre una dimensión negativa y otra positiva del concepto de libertad. La preocupación de Raz aquí es otra. Le interesa vincular el principio del daño (como criterio de legitimación penal) con el valor de la autonomía en el marco de una sociedad pluralista que practica la tolerancia y el respeto mutuo. Logrará dicha vinculación por medio de una interpretación prospectiva del principio del daño. Así, para Raz 'causar un daño a otro' importa privarle de bienes instrumentales de los que el individuo dispone para realizar un plan de vida propuesto. ${ }^{99}$ En esto se asemeja al segundo concepto de daño que ofrece Feinberg, ${ }^{100}$ ya revisado. El problema surge cuando Raz reconoce que en la intervención institucional del derecho a través del recurso a la coerción, inevitablemente se adelanta una justificación racional a la misma en base a un juicio valorativo sobre la rectitud de la acción que es causante del daño. Es decir, una acción que causa un daño típicamente será prima facie incorrecta en el sentido moral. Algo de esto habría de plantear Michael Moore al proponer la independencia conceptual de 'lo moral' respecto del concepto de injusto (cuando se refiere a la agencia injusta) en la dimensión de atribución de culpabilidad jurídico-penal. ${ }^{101}$ Entre otras razones, la necesidad de la distinción pasa por el reconocimiento del desarrollo de una 'ética social' que sostiene una práctica deliberativa de reconocimiento moral intersubjetivo que se caracteriza porque excede la mera preservación de convicciones morales privadas. Se trata de estándares compartidos por la comunidad y que sustentan la práctica de atribución de reproche, entre otras. ${ }^{102}$

La conclusión de Raz de la comprobación de esta moralidad prima facie de las acciones que provocan un mal es que al instalarse como componente necesarios del argumento justificatorio de la intervención jurídico-penal, impiden restringirlo y entonces, impiden argumentar en contra el reforzamiento de la moral por parte del derecho. ${ }^{103} \mathrm{El}$ modo en que Raz resuelve este dilema que se aparece a la manera de 'la paradoja' de MacCormick es a través de una reinterpretación de la importancia de la autonomía como valor moral. Según Raz, el 'daño' como criterio legitimador (y limitador) permite su derivación del principio de autonomía (como ya veíamos); pues bien, desde aquí hay un solo paso para argumentar que el

\footnotetext{
${ }^{99}$ Ibid., p.327.

100 Feinberg, J., Harm to Others, p. 33.

101 Moore, M., The independent moral significance of wrongdoing, Journal of Contemporary Legal Issues, 237, 1994, pp. $237-281$.

102 Ibid., p. 247.

103 Raz, Autonomy, Toleration and the Harm Principle, p. 328.
} 
derecho no sólo cumple la función de impedir el daño a otros, en el sentido de obstaculización de la realización autónoma de planes de vida, sino que también el deber positivo de promover la realización autónoma de otros. Y eso requiere una reinterpretación del daño como quebrantamiento de un estándar más general de justicia, y la intervención del Estado como un intento de restablecimiento de dicha justicia. ${ }^{104}$

Muchas de las cuestiones que se discuten respecto del estatus de la moralidad que los liberales anti-moralistas pretenden dejar fuera del alcance del derecho y los conservadores moralistas pretende reforzar por medio de éste salieron a la luz por primera vez en el siglo XX en el muy conocido debate entre Hart y Devlin a propósito de la pregunta - precisamente - (aprovechando la resolución de nuestro Tribunal Constitucional con la que se dio inicio a esta discusión) por la tematización jurídico-penal de la sodomía. Antes de reproducir la totalidad del debate y los alcances de éste en la filosofía moral y jurídica contemporánea, cuestión respecto de la cual la literatura es abundante, ${ }^{105}$ quisiera usar el concepto hartiano de moral como catapulta para lidiar con el problema de la aproximación (antes que pura conceptualización) por parte del liberalismo anti-

104 Ibid., p. 329.

105 El libro que da inicio al debate por medio de una crítica a la monografía de Devlin ya citada es Hart, H.L.A., Law, Liberty and Morality, Stanford University Press, U. of California, 1963. En general sobre el debate Hart-Devlin véase George, Making men moral, pp.48 y ss. En la obra de Feinberg véase Harmless Wrongdoing, pp. 133 y ss. Para un comentario por parte de Feinberg de la crítica de Hart que aquí se comentará p. 140. Para la réplica de Devlin a la crítica (que aquí no abordaremos) véase p. 144. También Feinberg, Some unswept debris from the Hart-Devlin debate, Synthese, Vol. 72, $\mathrm{n}^{\circ} 2$, Kurt Baier Festschrift, Part II, 1987, pp. 249 - 275. Por ultimo, recientemente Cane, P., Taking Law seriously: Starting points of the Hart/Devlin debate, 'The Journal of Ethics', Vol. 10, n¹/2, 2006, pp. 21 - 51. En términos generales, la crítica de Hart a Devlin en Law, Liberty and Morality se organiza en tres puntos de divergencia. El primero apunta al consecuencialismo que resalta el beneficio del pluralismo y de la divergencia. Consiste en una asunción hipotética de la pretensión de integración social' de Devlin. ¿Qué valor tiene, pregunta Hart, una sociedad en la que lo extraño, lo divergente, lo otro, al ser tratado como ajeno, es perseguido y criminalizado? Para Hart, una sociedad así descrita no puede tener ningún valor y no puede el existir el deseo de mantener dicha sociedad integrada (Law, Liberty and Morality, p. 19). El segundo punto de la crítica que creo merece atención es la referencia al ámbito de la agencia cuya represión (abstención por parte de los ciudadanos) es exigida por el derecho. Hart afirma de modo muy lúcido que el costo es mucho mayor en el caso de la abstención de realizar actos sexuales que responden a impulsos de esa naturaleza (propiamente sexuales), que en casos de delitos contra la vida o la propiedad de otro (p. 22). Claro está, no es muy nítida la observación si se tiene en cuenta la eventual objeción de la categoría general de 'delitos contra la autonomía sexual de otros'. Pero tratándose de delitos de 'mera inmoralidad' la observación es ciertamente pertinente. Por último, el tercer punto que creo relevante comentar dice relación con lo que Hart califica como un 'abuso de ejemplos' por parte de los críticos - en general - de J.S.Mill y de su tradición. En el caso de Devlin, Hart deja al descubierto de qué forma la apelación a un cierto estándar de comportamiento moral para explicar la lógica de la punibilidad de la violación con el consentimiento de la víctima, deriva en una mera confusión entre moralismo (protección de 'la moral') y paternalismo (protección del consentimiento de individuos en actos dañinos para éstos) (pp. 30 - 31). Lo mismo se aplica para el paternalismo en el caso del uso de drogas (p. 32). 
moralista al fenómeno moral y su relación con el derecho (penal). Una cuestión, aunque el lector no se convenza de ello, todavía no tratada.

En Law, Liberty and Morality a propósito de su defensa del principio del daño de J.S. Mill y contra sus críticos (principalmente Devlin, quien a nosotros nos interesa), Hart desarrolla una notable distinción entre una moral 'positiva' y una 'crítica'. ${ }^{106} \mathrm{El}$ punto de la distinción es el hincapié en la aptitud de la moral como ejercicio de razón práctica crítica hacia la justificación racional de ciertas instituciones. Según Hart, independiente del estado actual de la moral de una determinada sociedad (moral 'positiva'), el potencial crítico de la moral evidencia que su naturaleza está lejos de ser estática, y es por el contrario, dinámica. Se manifiesta a través del ejercicio de una racionalidad práctica que cuestiona la rectitud de ciertas instituciones mediante la aplicación de ciertos principios generales de la razón. Esto puede entenderse como un proceso de corrección normativa moral (a través del ejercicio de reglas de reconocimiento morales como el imperativo categórico o sus variantes modernas, tales como el principio de universalidad U o la posición original) o como el ejercicio de un juicio crítico en sentido amplio. ${ }^{107}$

Ya sea se trate de un juicio crítico hacia el derecho vigente, o la aplicación de una regla de reconocimiento moral, no cabe duda que dicha postura crítica asume de modo automático la tarea de enfrentarse al carácter constitutivo de las reglas que imprimen en cierta práctica humana la valoración que la comunidad hace de dicha práctica (es decir, el sustento moral que en la práctica subyace a las instituciones jurídicas). Éste resulta el momento adecuado para reflexionar de forma general en torno a la operatividad de ciertas construcciones meta-éticas en la forma de reglas de reconocimiento moral y su aproximación crítica a instituciones jurídicas que lidian, en principio, con criterios de distribución de autonomía; como es el caso aquí, de la autonomía sexual. En efecto, pues ¿qué puede estar entendiendo Hart de modo concreto por moral 'positiva' y moral 'crítica' respectivamente? Como sabemos, el ejercicio de una moral auténticamente crítica no está ni puede estar reservado a especialistas: moralistas, religiosos o científicos. Es característico de un proceso de reflexión normativa moral el estar precedida por un estadio de ethos pre-reflexivo accesible al ciudadano común y corriente. En dicho estadio de absoluta 'pureza' reflexiva, el individuo contrasta acciones hipotéticas con normas que funcionan como criterios aprehendidos por el sujeto a través de diversos mecanismos, cognoscibles o no. ${ }^{108}$ Desde este estadio existe naturalmente un paso casi insensible a un primer nivel de reflexión, que podemos

\footnotetext{
106 Hart, Law, Liberty and Morality, p. 20.

107 Aquí favorezco la propuesta analítica neo-contractualista scanloniana, en lo que respecta al tratamiento de las razones y los valores en el marco de una teoría de la moral contractual. Véase sobre la teoría Wallace, R.J., Scanlon's contractualism, Ethics, Vol. 112, n³, Symposium on T.M.Scanlon's 'What We Owe to Each Other', 2002, pp. 429 - 470.

108 Maliandi, R., Ética: conceptos y problemas, Cap. 2: Niveles de reflexión ética, Buenos Aires, Biblios, 2004, p.47.
} 
denominar 'reflexión moral' y se caracteriza por su grado de especialidad, de aplicación de conocimiento técnico y seriedad en la prédica de estándares normativos. ${ }^{109}$ Por último, el así llamado estadio de 'ética normativa' propiamente tal se caracteriza por la generación de normas con capacidad de corrección, y por el cuestionamiento crítico de la validez de ciertos principios morales asentados. ${ }^{110}$

Ahora bien, puede ser que el esquema descrito se acople o no de modo más o menos apropiado a las descripciones más autorizadas con que contamos de los mecanismos de ejecución de los criterios de corrección normativa moral disponibles (imperativo categórico, principio U o posición original). Mas, por lo pronto, cuando se hace alusión a los "principios (de la moral) invocados para criticar ya sea las instituciones que refuerzan la moral positiva como también dicha moral en sí misma" podemos aceptar que se trata de principios generados en base a un ejercicio procedimental de racionalidad práctica de un modo similar a lo descrito aquí.

Ahora bien, hasta aquí nadie dudaría que dicho ejercicio no sólo es admisible, sino indispensable para la salud de una sociedad democrática y un Estado de Derecho que cultiva (a la manera de Raz y MacCormick) el valor moral de la tolerancia. Entonces ¿cuál puede ser el problema?

Según Hart, la importancia de distinguir un determinado orden moral asentado en una cultura (moral positiva) de un ejercicio crítico de racionalidad práctica (moral crítica) radica en que, de ese modo, se disipan algunas dudas respecto al objetivo concreto del reforzamiento moral a través del derecho como fenómeno. ${ }^{111}$ Como se sabe, como 'reforzamiento de la moral' se pueden designar una variedad de situaciones. La preocupación de Hart es la separación de la referencia a una moral como respuesta a la pregunta por aquél objeto de reforzamiento por parte del derecho, de la referencia al principio del daño (por ejemplo) como criterio moral cuya justificación se aparece ante nosotros también tematizada moralmente.

Independiente del tratamiento que Hart da a la controversia, ${ }^{112}$ nunca queda por completo claro (así como tampoco respecto de la moral crítica) qué se quiere decir cuando se hace referencia a la 'moral positiva'. Naturalmente, y de modo intuitivo, el concepto parece hace referencia a un conjunto de valores, que como sistema (de valores y de normas) evidencia una estructura firme y sostenible en el tiempo. Se puede postular aquí como teoría candidata para dotar de plausibilidad a la práctica de la cultivación de valores entendidos como expresiones de la

\footnotetext{
${ }^{109}$ Ibid., pp. $52-53$.

${ }^{110}$ Ibid., pp. $54-57$.

111 Hart, Law, Liberty and Morality, pp. 22 - 24.

112 Un tanto marginal si se compara con el proyecto general del artículo. Véase Ibid., p. 23.
} 
estructura de una sociedad, la propuesta por Joseph Raz, ${ }^{113}$ la cual, como se sabe, desarrolla un complejo de relaciones entre lo que son dos teorías básicas - las así llamadas tesis 'especial' y 'general' sobre la dependencia de los valores - sobre la relación entre valores y prácticas sociales en que se sustentan, cuyo manejo lleva a la conclusión no relativista de la dependencia de los valores respecto de las prácticas. ${ }^{114}$

Ahora bien, la utilidad de la imagen de un sistema de valores (ya sea en la versión del liberalismo de Raz o en el neo-contractualismo de Scanlon) radica en que, con este aparato conceptual es posible luego reconocer el conjunto de valores así propuesto como representando la identidad de una comunidad determinada. Así es como llegamos a referirnos a una "moral social" o "moral positiva". Su utilidad como recurso retórico es la de permitir el reconocimiento de un legítimo contradictor - antónimo del ejercicio libre y autónomo de un plan de vida personal. De este modo, al plantear la existencia de un conjunto de valores que se manifiesta como el reflejo de la moral vigente en una sociedad, se puede proceder a cuestionar de modo serio y a través de un juicio de ponderación, su importancia respecto de los derechos derivados del valor de la autonomía, que pueden entrar en conflicto con aquél.

Lo que se denomina 'versión fuerte de la tesis liberal' concluye luego de dicho ejercicio de ponderación la "prioridad del reconocimiento del derecho individual a la configuración autónoma del plan [de vida] personal" por sobre el interés colectivo en reforzar la vigencia de la moral social. ${ }^{115}$ Claro está, dicha presentación de la aproximación liberal a la cuestión, no se corresponde con el ejercicio concreto de la potestad punitiva fragmentaria. ${ }^{116} ¿$ Cuál es el resultado al que llega Hart? Sostengo en este trabajo que la conclusión de Hart, más allá de la réplica a los críticos de Mill, es bastante más difusa de lo que se espera. Más allá de las críticas concretas al moralismo impuro de Devlin (catalogado por Hart como un representante de lo que él denomina 'tesis moderada') ${ }^{117}$ - tesis que destaca por incurrir en la ya mencionada confusión entre paternalismo y moralismo, y la equiparación irreflexiva entre la tematización penal de atentados contra la vida o propiedad y atentados contra la autonomía sexual - el desarrollo de una posición liberal propia no asume ningún compromiso con la diferenciación categórica entre daño y reforzamiento moral. Si bien Hart reconoce la operatividad del principio del daño como criterio evaluativo (al describir la caricatura de un argumentador utilitarista haciendo uso del criterio en su defensa de un reforzamiento moral ${ }^{118}$ su

\footnotetext{
113 Raz, J., The Practice of V alue, 'The Tanner lectures on Human Values', U. of California, Berkeley, March, 2001, pp. 113 - 150.

114 Otro ejemplo amigable y cercano es la versión del así llamado 'pluralismo de valores' que se desarrolla en Orellana, M.E., Pluralismo: una ética del siglo XXI, Santiago de Chile, Universidad de Santiago de Chile, 1996.

115 Bascuñán, A., El derecho penal sexual moderno, ¿afirma seriamente lo que dice? V SELA, 2009, nota 19.

116 Ibidem.

117 Hart, Law, Liberty and Morality, p. 48.

${ }^{118}$ Hart, Law, Liberty and Morality, p. 23
} 
conclusión de la razón de la 'inmoralidad' de la conducta homosexual privada en contraste con el 'daño' causado por la conducta homosexual (o cualquier conducta sexual) en público como indecencia (clave - sostengo - para definir la postura por la que se tomará partido) parece débil y un tanto difusa. ${ }^{119}$ Claro está, esto se puede resumir simplemente destacando que el intento de revival del principio del daño milliano llevado adelante por Hart, no es tan fuerte como el proyecto que posteriormente asumiría Feinberg.

¿Por qué nos interesa destacar este carácter de la crítica liberal de Hart al conservadurismo? Porque en gran parte demuestra que una forma posible que puede asumir el debate 'moralismo-liberalismo' es la de un conflicto que llama a un ejercicio de ponderación: entre el valor de la autonomía y el valor de una moral positiva dada. Aunque todavía el lector no sea capaz de convencerse, la reinterpretación del debate en estos términos no resuelve de modo satisfactorio el problema de la toma de postura liberal frente a la posibilidad de un agnosticismo radical o de un moralismo moderado. La cuestión del modo en que ha sido hasta aquí presentada favorece el moralismo moderado, propio de la consideración a favor de un reforzamiento por parte del derecho, de la autonomía, en tanto valor moral, que derrota la consideración favorable al reforzamiento de un sistema de valores colectivo. La cuestión de si es ésta una estrategia propiamente moralista (moderada-liberal) ha ocupado un espacio en un intercambio entre Sandel y Moore al respecto. Michael Sandel ofrece un esquema ilustrativo de las distintas posturas que es posible asumir en lo que respecta a la relación entre el derecho y la moral. ${ }^{120}$ Una concepción 'ingenua' vincula la justicia del derecho con el valor moral de las conductas que refuerza o prohíbe. Luego una concepción 'sofisticada' plantea deducir la justicia de una 'teoría de la justicia' propiamente tal, que adscriba un cierto valor a la regla de la mayoría y en general tenga la aptitud de reconducir el problema al paradigma democrático. Esta última concepción a su vez puede asumir cuatro formas; esto es, se puede ser sofisticado y: relativista - en alusión al relativismo moral - utilitarista - asocia la bondad de la neutralidad moral con la regla de la mayor utilidad - voluntarista -se toma en serio el así llamado 'mandato de neutralidad' por cuanto el ejercicio libre de decisión y ejecución de planes de vida personal por parte de los ciudadanos constituye un bien en sí mismo - y minimalista - para quien la política debe ser neutral precisamente en aquellos ámbitos de la vida en que el desacuerdo es inevitable. Se espera entonces la generación de un 'consenso por superposición' que demuestre el grado de acuerdo que son capaces los individuos de lograr cuando existen medios institucionales para ventilar y solucionar el desacuerdo. ${ }^{121}$

Apoyado en este esquema, Sandel ofrece a continuación una visión del así llamado 'derecho a la privacidad' (clave para resolver las disputas constitucionales

\footnotetext{
${ }^{119}$ Ibid., p. 46.

${ }^{120}$ Sandel, M., Moral argument and Liberal Toleration: Abortion and Homosexuality, en Dworkin, G., (ed), 'Morality, Harm and the Law', Westview Press, pp. 109 - 123.

${ }^{121}$ Ibid., p. 110.
} 
que en este artículo hemos comentado), donde propone distinguir al menos dos paradigmas. Según Sandel, es posible observar un 'viejo' derecho a la privacidad y un 'nuevo' derecho. El cambio de paradigma se deduce del uso argumentativo jurisprudencial y de los distintos ámbitos de reconocimiento de los derechos. En términos simples, el 'viejo' derecho se traducía en la capacidad para exigir que ciertos hechos definitorios de la personalidad de un individuo se mantuviesen lejos de la esfera de opinión pública. Se trataba de una manifestación del derecho a la honra y resistía reconocimiento jurisprudencial a nivel de reparación civil por daños a la honra causados por la difusión de cierta información. Hoy, el 'nuevo' derecho a la privacidad gira hacia el reconocimiento de libertad agencial en orden a involucrarse en actividades propias de toda persona humana realizadas en la privacidad del hogar y dota de razonabilidad a la reclamación de que estas conductas sean inmunes o ajenas a la regulación del derecho y ciertamente al alcance de la opinión de la esfera pública. ${ }^{122}$

Ahora bien, prosigue Sandel haciendo uso más allá de esta última distinción, de un binomio formado por dos posturas igualmente liberales que es posible asumir frente a la pregunta por la justificación de la libre agencia en privado ( $y$ esto es lo que nos interesa). Según Sandel, en lo que aquí respecta se puede asumir una postura voluntarista - comprometida con el mandato de neutralidad del derecho a tal punto que no admite incorporar un juicio de evaluación de la rectitud de la acción en cuestión - o sustantiva - que apela a la 'rectitud' o 'bondad' de la práctica que se ejecuta para promover su realización e impedir su obstaculización por el derecho. ${ }^{123}$ Según Sandel el argumento disidente en Bowers v. Hardwick se caracteriza por adoptar el punto de vista voluntarista puesto que no asume ningún compromiso con el valor moral que tiene la expresión libre de la sexualidad humana, sino más bien hace suya la conclusión del silogismo práctico básico: siendo los homosexuales hombres, tienen derecho a desarrollar un plan de vida personal lejos de la esfera del derecho, porque ese es un derecho de todos los hombres en tanto ciudadanos del Estado. ${ }^{124}$ Para Sandel, un argumento sustantivo habría tenido que incorporar una analogía con el carácter sagrado del matrimonio, o la importancia que tiene para el ser humano la manifestación libre de su sexualidad. ${ }^{125}$

Ahora bien, nos interesaba destacar en el análisis de Sandel las opiniones jurisprudenciales liberales en el voto disidente de Bowers porque a continuación M.S. Moore en su célebre obra sobre Derecho penal ${ }^{126}$ habría de llevar las distinciones ofrecidas por Sandel a un nivel de desarrollo aún superior y

\footnotetext{
122 Ibid., p. 112.

123 Ibid., p. 117.

124 Ibid., p. 118.

125 Observa que una aproximación de ese tipo se aprecia en la opinión jurisprudencial de la Corte de Apelaciones, en Ibídem.

${ }^{126}$ Moore, M., Placing Blame, Oxford University Press, Oxford, 1997.
} 
demostraría con ello que: primero, ser un liberal sensato no es algo fácil, y segundo, que existen distintas maneras de ser liberal.

Moore en la sección de su obra cuyo título revela su pretensión de "retaxonomizar" las posturas ya existentes en torno a la cuestión del reforzamiento de la moral, describe dos posibles posturas 'ingenuas' (usando la jerga de Sandel): una consecuencialista y otra no consencuencialista. Criticará a Sandel por dejar de ver la última de las opciones, lo que revela por lo demás que en su teoría confunde una pregunta de teoría política - sobre la posibilidad de promover fines morales a través de la legislación - con una de filosofía moral - sobre la relación entre la bondad que se predica de un objeto y la rectitud de cierta acción que pretende la búsqueda del mismo. ${ }^{127}$ Luego prosigue Moore en lo relativo al punto de vista ingenuo. Moore lo comparte en algún sentido al igual que Sandel, ${ }^{128}$ pero se aparta de él porque, explica, considera que su simpatía por el punto de vista ingenuo deviene en un rechazo infundado hacia el punto de vista sofisticado, en particular hacia sus formas voluntaristas y minimalistas. Este reclamo de rechazo infundado (podríamos decir: difuso o débil) constituye el punto de partida de la visión amplia y crítica hacia el liberalismo y sus tomas de postura que Moore ofrecerá más adelante. Aquí Moore le reclama a Sandel el creer que 'voluntarismo' significa exigir un cierto grado de acuerdo o cooperación en la sociedad respecto a la cualidad moral de cierta actividad para que exista o no una invasión a la libertad de acción por parte del derecho. Así, la sociedad tendría que estar de acuerdo en que la homosexualidad en sí misma no es inmoral para que la cuestión sobre la restricción de libertad en dicho ámbito de la vida no generara conflictos. ${ }^{129}$ Aquí se encuentra el punto más lúcido, cuando se sostiene que para un liberal-voluntarista, la realidad ontológica de los derechos morales torna irrelevante su funcionamiento práctico en el nivel de las instituciones. El ejercicio de una capacidad crítica respecto del respeto a la autonomía y tolerancia es más fuerte como medio de solución de conflictos que la discusión sobre la naturaleza del derecho derivado del reconocimiento constitucional o del código penal de que son titulares (por ejemplo) los homosexuales. De nuevo prima la autonomía por sobre (ahora) cualquier desacuerdo moral que podamos tener sobre una conducta que es precisamente (o únicamente) tematizable moralmente.

El reto de Moore (entonces) al liberal es que sea capaz de entender que:

"A society of sincere liberals could easily achieve harmony and co-operation without resolving their first-order differences about the morality of practices like abortion and homosexuality, as long as they strongly believed in the rightness of tolerance, pluralism and autonomy. To think otherwise is to

\footnotetext{
${ }^{127}$ Ibid., pp. $650-651$.

${ }^{128}$ Ibid., p. 652

${ }^{129}$ Ibid., p. 654.
} 
Gallego - El problema del legalismo legal en el derecho penal

postulate some instinct of moral imperialism that I do not think is very
plausibly an aspect of buman nature

¿Qué entiende Moore aquí por imperialismo (de la) moral? La idea de que el desacuerdo sobre la moralidad de ciertas conductas es de primer orden sugiere que podemos introducir una meta-regla o regla de segundo orden que excluye, en ciertos casos, ciertas consideraciones que favorecen alguna postura propiamente moral respecto a la ejecución de las conductas por parte de los individuos que serán objeto de discusión. El problema, como lo muestra una contribución de Carl F. Cranor, ${ }^{131}$ es que es posible mantener dentro del ámbito de lo moral el establecimiento de dicho principio o regla de segundo orden. Así, según Cranor, el punto del moralismo legal es la elección de los mecanismos para la satisfacción de lo que llama un principio de la moral de segundo orden, que exige el reforzamiento de la conclusión sobre la moralidad de cierta actividad a la que se llega haciendo operativo un principio de primer orden. La naturaleza de dicho principio dependerá de si se adscribe a una moral utilitarista, kantiana o neocontractualista. ${ }^{132}$ Así, R.P.George en su reseña a Harmless Wrongdoing sostendrá que la defensa de Feinberg de la postura liberal (anti-moralista) es una defensa moralista, en el sentido de que provee razones morales para rechazar el reforzamiento de la moral por el derecho. ${ }^{133}$ Según George, Feinberg insiste en la inmoralidad de la legislación que pretende el reforzamiento de la moral. ${ }^{134}$ ¿Qué tipo de liberalismo profesa Feinberg al hacer esta reclamación? Según George, hay dos posibilidades (refiriéndose a una postura liberal estándar): o bien se es un relativista extremo respecto de la moral, o bien se es un relativista relativo. El relativista relativo cree que un juicio moral sobre conductas no dañosas (por ejemplo las realizadas en privado con el consentimiento de los participantes) es por definición relativista, o mejor, en el ámbito de las conductas no dañosas es necesario ser relativista. Esto porque existe una verdad incuestionable que derrota toda otra consideración: el valor del respeto a la autonomía de los ciudadanos que deciden consentir a la realización de ciertas actividades en privado. Los juicios morales sobre conductas que se manifiestan como expresiones de la autonomía individual, no resisten otra caracterización que puramente subjetivos, y por ende, relativos. ${ }^{135}$ Ésta puede ser la línea de Raz, y un modo de asumir el compromiso a que nos llama Moore. Sin embargo, argumenta George, Feinberg no es ni un relativista ni profesa el valor de la autonomía de este modo. ¿Dónde se encuentra el origen de su defensa moralista por una legislación neutral? En un compromiso serio con el principio de neutralidad, como criterio evaluativo de la actividad del legislador. Feinberg estará dispuesto, según George, a conceder que las prácticas

\footnotetext{
130 Ibid., p. 657.

${ }^{131}$ Cranor, C., Legal Moralism Reconsidered, Ethics, Vol. 89, n²2, 1979, pp. 147 - 164.

132 Ibid., pp. 152 - 153

133 George, R.P., Recview: Moralistic Liberalism and Legal Moralism, Michigan Law Review, Vol. 88, nº, 1990 Survey of Books Relating to the Law (May, 1990), pp. 1415 - 1429.

${ }^{134}$ Ibid., p. 1417.

135 Ibid., p. 1418.
} 
en cuestión son inmorales, sin embargo no es éste un juicio a que esté autorizado el legislador. Su tarea se limita a verificar que un bien jurídico cuya titularidad manifieste la concesión de autonomía a los individuos como ideal político, sea protegido, o que la conducta cuya tematización jurídico-penal se pretenda, cause daño o sea ofensiva a terceros no partícipes. ${ }^{136}$

Ahora bien, naturalmente, que ésta sea la mejor interpretación del intento de depuración feinbergeriano, que lo distancia de Raz y del rol que la autonomía juega en la aproximación teórica a la pregunta por la legitimidad material del derecho penal, es una cuestión abierta y no llamada a finiquitarse prontamente. En nuestra discusión dogmática, parece estar por otro lado ausente. Una explicación que puedo ofrecer es la excesiva fijación (que corroe al presente artículo por cierto) por delimitar cuestiones de justificación y cuestiones de legitimación (material). Sostengo que en el caso presente ( $\mathrm{y}$ en muchos otros casos, como por ejemplo la pregunta por el fundamento de la imposición de la sanción penal al extranjero, hasta ahora sólo tematizada como un problema de la dimensión de la legitimidad formal y que sin embargo admite ser abordada como un problema de justificación) la distinción se torna a ratos difusa, a favor de la aproximación liberal a la pregunta por la tematización penal de conductas no lesivas a terceros.

Volviendo a la obra de Feinberg, la cuestión es sensible considerando que, en un célebre trabajo anterior del autor, se postuló de un modo que resultó infinitamente influyente para la doctrina posterior, que la característica singular de la sanción propiamente penal, era la condena moral que conlleva su imposición. ${ }^{137}$ Lo que hoy conocemos como 'función expresiva de la pena', que hace referencia a la función simbólica que cumple la pena como medio convencionalmente reglado para expresar condena, desaprobación y reproche por la acción contraria a derecho ejecutada por el culpable, nos dificulta la tarea de conciliar nuestras convicciones morales de primer orden (intuiciones morales básicas) con el respeto - tanto en la dimensión de la intersubjetividad como en la política - al valor de la autonomía, y con el principio o mandato de neutralidad por último como criterio de legitimación o justificación de la práctica punitiva estatal. Según B.E. Harcourt, en la obra de Feinberg lo que encontramos es propiamente el establecimiento en un primer orden de los límites morales que definen luego los contornos de la teoría de justificación de la práctica punitiva ${ }^{138}$ Esta íntima interrelación entre legitimación y justificación es rara vez notada en la dogmática y termina por manifestarse propiamente (al menos en la interpretación que Harcourt hace de Feinberg) en la dimensión del principio de proporcionalidad, que exige que se confirme la tesis normativa de Feinberg, cual es, que la "expresividad" de la

\footnotetext{
${ }^{136}$ Ibid., p. 1419.

${ }^{137}$ Feinberg, J., The expressive function of Punishment, en del mismo 'Doing \& Deserving', Princeton: Princeton University Press, 1970. Para una definición de función expresiva véase p. 98.

${ }^{138}$ Harcourt, B.E., Joel Feinberg on Crime and Punishment: Exploring the Relationship Between The Moral Limits of the Criminal Law and The Expressive Function of Punishment, Buffalo Criminal Law Review, Vol. 5, n 1 . Symposium: The Moral Limits of the Criminal Law, 2001, pp. 156 y ss.
} 
pena, en términos del quantum de condena moral, depende del daño causado a otros que la norma de comportamiento quebrantada pretendía evitar. ${ }^{139}$

\section{CONCLUSIÓN}

El apartado anterior muestra, por un lado, que la pregunta por la legitimidad material de la práctica punitiva debe resolverse apelando a nuestras intuiciones básicas sobre nuestra constitución política y los principios morales de primer orden con los que estamos comprometidos. Muestra, en segundo lugar, que en esa dimensión se encuentran la pregunta por la legitimación material con la pregunta por la justificación. La propuesta de W. Sadurski es una muestra de dicha interrelación. ${ }^{140}$ Quien comienza intentando encontrar una estrategia de justificación que asuma el problema de la insatisfacción del estándar de justicia distributiva o la desigual repartición de esferas de autonomía individual, termina postulando un compromiso con el ideal de autonomía que excluye consideraciones moralistas o paternalistas al momento de proceder a la tematización jurídico-penal de conductas. Es lo mismo que ocurre cuando M. Matravers, en la obra en que intenta encontrar la teoría moral o política que subyace a la pregunta por la justificación de la práctica punitiva estatal, concede al escéptico (al que se sitúa en el punto de partida de Sadurski) que la desigualdad material previa impide hacer referencia a un castigo penal propiamente tal sino a un puro ejercicio de coerción. ${ }^{141}$ Aquí planteamos que una desigualdad previa en términos de la consideración más o menos desfavorable hacia las minorías sexuales (por ejemplo) exige para salvar el déficit de justificación un compromiso con alguna de las estrategias teóricas discutidas a lo largo del aparato anterior: principio de autonomía como meta-regla, relativismo moderado, principio de proporcionalidad como manifestación del acotamiento de la discusión que produce la función expresiva como elemento de una teoría de justificación, u otro.

La importancia de contar con un aparato conceptual propio de filosofía política y moral que nos permita superar la moral arguphobia - y entonces escapar de los límites impuestos a la discusión por la operatividad del criterio del bien jurídico o de la lesividad del acto - pasa por reconocer aquellas instancias en que, dada la configuración institucional de los organismos que intervienen, las discusiones se elevan a dichos foros. Me refiero a un organismo que ejerza jurisdicción constitucional a propósito de la pregunta por la legitimidad material de una norma penal que sanciona conductas no lesivas y por razones aparentemente moralistas. Así, considerando que nuestro Tribunal Constitucional, al hacer frente a normas penales como el art. 365 del código penal (y eventualmente a la norma que prohíbe el incesto, el aborto, la indecencia pública o el almacenamiento de pornografía

\footnotetext{
139 Ibid., p. 157.

${ }^{140}$ Véase supra nota 8.

141 Matravers, M., Justice and Punishment. The rationale of coercion, Oxford University Press, 2000, pp. $266-267$.
} 
REJ - Revista de Estudios de la Justicia - No 14 - Año 2011

infantil) no sólo deberá adscribir a una concepción del concepto de igualdad, vida privada o libertad (los derechos que en esos casos serán invocados para reclamar la inconstitucionalidad de las normas de comportamiento que correspondan) sino que también de los conceptos moralidad y cultura, se hace necesario que la dogmática (penal) trabaje en una línea paralela discutiendo estos conceptos de un modo más sofisticado a como lo ha venido haciendo. 
Gallego - El problema del legalismo legal en el derecho penal

\section{BIBLIOGRAFÍA:}

* AMDUR, Robert: "Review: Harm, Offense, and the limits of liberty", Harvard Law Review, Vol. 98, n8, 1985.

* BASCUÑÁN, Antonio: "Derechos fundamentales y Derecho penal”, en Revista de Estudios de la Justicia $\mathrm{n}^{\circ}$ 9, 2008. 2009.

"El derecho penal sexual moderno, ¿afirma seriamente lo que dice?”, V SELA,

* CANE, Peter: "Taking Law seriously: Starting points of the Hart/Devlin debate", The Journal of Ethics, Vol. 10, n¹/2, 2006.

* CORLETT, J. Angelo.: "The philosophy of Joel Feinberg", The Journal of Ethics, Vol. 10, $n^{\circ} 1 / 2,2006$.

* CRANOR, Carl: “Legal Moralism Reconsidered”, Etbics, Vol. 89, n², 1979.

* DALTON, Harlon: "Review: 'Disgust' and punishment", The Yale Law Journal, Vol. 96, $n^{\circ} 4,1987$.

* DEVLIN, Patrick: "The enforcement of morals", Oxford University Press, London, 1965.

* DWORKIN, Ronald: "Lord Devlin and the Enforcement of Morals", The Yale Law Journal, Vol. 75, n6, 1966.

"Morality, Harm and the Law", Westview Press.

* DYBIKOWSKI, James C.: "Lord Devlin's morality and its enforcement", Proceedings of the Aristotelian Society, New Series, Vol. 75 (1974 - 1975).

* FEINBERG, Joel: "The Moral limits of the Criminal Law", Oxford University Press, Oxford, 1984.

"Some unswept debris from the Hart-Devlin debate", Synthese, Vol. 72, n², Kurt Baier Festschrift, Part II, 1987.

"The expressive function of Punishment", en del mismo Doing \& Deserving, Princeton: Princeton University Press, 1970.

* FREUD, Sigmund: El malestar en la cultura, (trad. Luis López-Ballesteros), Ed.Folio S.A., 2007.

* GEORGE, Robert P: "Making men moral", Oxford University Press, USA, 1995.

"Recview: Moralistic Liberalism and Legal Moralism", Michigan Law Review, Vol. 88, $\mathrm{n}^{\circ}$ 6, 1990 Survey of Books Relating to the Law (May, 1990).

* HARCOURT, Bernard: "The collapse of the harm principle", The Journal of Criminal Law and Criminology, Vol. 90, n¹, 1999.

"Joel Feinberg on Crime and Punishment: Exploring the Relationship Between The Moral Limits of the Criminal Law and The Expressive Function of Punishment", Buffalo Criminal Law Review, Vol. 5, $\mathrm{n}^{\circ}$ 1. Symposium: The Moral Limits of the Criminal Law, 2001.

* HART, Herbert Lionel Adolphus: El Concepto de Derecho, Trad. Genaro Carrió, AbeledoPerrot, Buenos Aires.

Law, Liberty and Morality, Stanford University Press, U. of California, 1963.

* HÖRNLE, Tatjana: "La protección de sentimientos en el STGB”, en Hefendehl, R., (ed.) La teoría del bien jurídico, Marcial Pons, Madrid, Barcelona, 2007.

* HUSAK, Douglas: Pbilosophy of Criminal Law, Rowman \& Littlefield, Estados Unidos, 1987.

* KINDHÄUSER, Urs: "Reflexiones de teoría de las normas acerca del consentimiento en el Derecho Penal", en del mismo, Teoría de las normas y sistemática del delito, Ara, Lima, 2008.

"La fidelidad al derecho como categoría de la culpabilidad", en Kindhäuser y Mañalich, Pena y culpabilidad en el Estado democrático de derecho, Ara, Lima, 2009. 
* KLARMAN, Michael: "Brown and Lawrence (and Goodridge)", Michigan Law Review, Vol. 104, n³, 2005.

* MACCORMICK, Neil: "A moralistic case for a-moralistic Law”, Valparaiso University Law Review, Vol. 20, nº1, 1985.

* MALIANDI, Ricardo: Ética: conceptos y problemas, Cap. 2: Niveles de reflexión ética, Buenos Aires, Biblios, 2004.

* MAÑAliCH, Juan Pablo: "La prohibición de infraprotección como principio de fundamentación de normas punitivas. ¿Protección de los derechos fundamentales mediante el derecho penal?”, en Revista Derecho y Humanidades, No 11, Santiago, 2005.

* MATRAVERS, Matt: Justice and Punishment. The rationale of coercion, Oxford University Press, 2000.

* MEIER, Robert, GEIS, Gilbert: Criminal justice and moral issues, Roxbury Publishing Company; 4th edition, 2005.

* MOORE, Michael: "The independent moral significance of wrongdoing", Journal of Contemporary Legal Issues, 237, 1994.

Placing Blame, Oxford University Press, Oxford, 1997.

* MORGAN, Seiriol: "Dark Desires", Ethical Theory and Moral Practice, Vol. 6, n 4, 2003.

* ORELlANA, Miguel: Pluralismo: una ética del siglo XXI, Santiago de Chile, Universidad de Santiago de Chile, 1996.

* OST, Suzanne: "Children at risk: Legal and societal perceptions of the potential threat that the possession of child pornography poses to society", Journal of Law and Society, Vol. 29, n³, 2002.

* OXMAN, Nicolás: Libertad sexual y estado de derecho en Chile, 1ª.Ed. Librotecnia, Santiago, Chile, 2007.

* PERSAK, Nina: Criminalising harmful conduct. The harm principle, its limits and continental counterparts, Springer Ed., 2007.

* PRIMORATZ, Igor: "Sexual morality: Is consent enough?", Ethical Theory and Moral Practice, Vol.4, n³, Cultivating Emotions, 2001.

* RAZ, Joseph: "Authority, Law and Morality", en Ethics in the Public Domain: Essays in the Morality of Law and Politics, 1995.

"Autonomy, Toleration and the Harm Principle", en Ruth Gavison (ed.), Issues in Contemporary Legal Philosophy. The influence of H.L.A Hart, Clarendon Press, Oxford, 1992.

"The Practice of Value", The Tanner lectures on Human Values, U. of California, Berkeley, March, 2001.

* RODRÍGUEZ, Luis: "Sobre la regulación de los delitos contra la integridad sexual en el Anteproyecto de Código Penal”, en Política Criminal n¹, A 1.

* RUSSELL, Bertrand: Por qué no soy cristiano y otros ensayos, edhasa, 2008.

* SADURSKI, Wojciech: "Theory of punishment, social justice, and liberal neutrality", Law and Pbilosophy, Vol. 7, N³, 1988 - 1989.

* SANCHEZ, Claudio: Delito de almacenamiento de pornografía infantil, Librotecnia, Santiago, Chile, 2010.

* SANDEL, Michael: "Moral argument and Liberal Toleration: Abortion and Homosexuality", en Dworkin, G., (ed), Morality, Harm and the Law, Westview Press.

* SCHÜNEMANN, Bernd: "El principio de protección de bienes jurídicos como punto de fuga de los límites constitucionales de los tipos penales y de su interpretación", en Hefendehl, R., (ed.) La teoría del bien jurídico, Marcial Pons, Madrid, Barcelona, 2007.

* SEHER, Gerhard: "La legitimación de la normas penales basadas en principios y el concepto de bien jurídico”, en Hefendehl, Roland (ed.), La teoría del bien jurídico, Ediciones Marcial Pons, Madrid, 2007.

* TIEDEMANN, Klaus: "Constitución y Derecho penal", Revista española de derecho constitucional, Año 11, n³3, 1991. 
Gallego - El problema del legalismo legal en el derecho penal

* VIAL, Tomás: "Homosexuales y autonomía sexual en la jurisprudencia reciente de la Corte Suprema norteamericana: El caso Lawrence v. Texas", en Revista Derecho y Humanidades $n^{0}$ 10, Universidad de Chile, Escuela de Derecho, 2004.

* WAlLACE, R. Jay: "Scanlon’s contractualism", Ethics, Vol. 112, n³, Symposium on T.M.Scanlon's 'What We Owe to Each Other', 2002. 